Linköping Studies in Science and Technology

Dissertation No. 1579

\title{
Ductile Failure in \\ High Strength Steel Sheets
}

Oscar Björklund

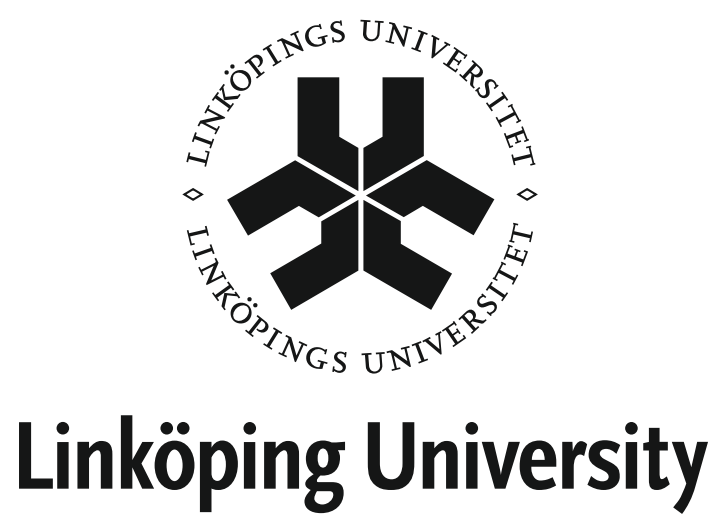

Division of Solid Mechanics

Department of Management and Engineering

Linköping University

58183 Linköping, Sweden

Linköping, March 2014 
Cover:

Results form finite element simulation of the stretching of the sheet metal exhaust bracket.

Printed by:

LiU-Tryck, Linköping, Sweden, 2014

ISBN 978-91-7519-389-2

ISSN $0345-7524$

Distributed by:

Linköping University

Department of Management and Engineering

58183 Linköping, Sweden

\section{(C) 2014 Oscar Björklund}

This document was prepared with $\mathrm{LT}_{\mathrm{E} X}$, March 7, 2014

No part of this publication may be reproduced, stored in a retrieval system, or be transmitted, in any form or by any means, electronic, mechanical, photocopying, recording, or otherwise, without prior permission of the author. 


\section{Preface}

The work presented in this thesis has been carried out at the Division of Solid Mechanics at Linköping University with financial support from the VINNOVA PFF project "Fail" and the SFS ProViking project "Super Light Steel Structures". Industrial partners DYNAmore Nordic, Outokumpu Stainless, Saab Automobile, Scania $\mathrm{CV}$, SSAB, Swerea IVF and Volvo Car Corporation are gratefully acknowledged for their support.

I would like to thank my supervisor, Professor Larsgunnar Nilsson for all his support and guidance during the course of this work. I also greatly appreciate all the friendship and support provided by my current and former colleagues at the Division of Solid Mechanics. Furthermore I enjoyed the collaboration with my co-authors Dr Rikard Rentmeester and Lic. Eng. Alexander Govik.

For their assistance during the mechanical testing and specimen preparation throughout this project I would like to thank Andreas Lundstedt at Outokumpu Stainless, Peter Ottosson at Swerea IVF, and Bo Skoog, Per Johansson, Sören Hoff and Ulf Bengtsson at Linköping University. Annethe Billenius at Linköping University is acknowledged for her help with guidelines and support during the microscopic study as well as Dr Thomas Borrvall at DYNAmore Nordic for support and guidelines concerning code implementations.

Finally, I would like to thank the people who are closest to me, my girlfriend Sandra, my family and my friends for all their support. I could not have done it without you.

Oscar Björklund

Linköping, March 2014

"An expert is a man who has made all the mistakes which can be made, in a narrow field."

Niels Bohr, Danish physicist 



\section{Abstract}

Developments in computer-aided engineering and the rapid growth of computational power have made simulation-driven process and product development efficient and useful since it enables detailed evaluation of product designs and their manufacturing processes. In the context of a sheet metal component, it is vital to predict possible failure both during its forming process and its subsequent usage. Accurate numerical models are needed in order to obtain trustworthy simulation results. Furthermore, the increasing demands imposed on improved weightto-performance ratio for many products endorse the use of high-strength steels. These steels often show anisotropic behaviour and more complex hardening and fracturing compared to conventional steels. Consequently, demand for research on material and failure models suitable for these steels has increased.

In this work, the mechanical and fracture behaviour of two high-strength steels, Docol 600DP and Docol 1200M, have been studied under various deformation processes. Experimental results have been used both for material characterisation and for calibration of fracture criteria. One major requirement as concerns the fracture criteria studied is that they should be simple to apply in industrial applications, i.e. it should be possible to easily calibrate the fracture criteria in simple mechanical experiments and they should be efficient and accurate. Consequently, un-coupled phenomenological damage models have been the main focus throughout this work.

Detailed finite element models including accurate constitutive laws have be used to predict and capture material instabilities. Most of the fracture criteria studied are modifications of the plastic work to fracture. Ductile tensile and ductile shear types of fracture are of particular interest in sheet metal applications. For these fractures the modification of the plastic work relates to void coalescence and void collapse, respectively. Anisotropy in fracture behaviour can be captured by the introduction of a material directional function.

The dissertation consists of two parts. The first part contains theory and background. The second consists of five papers. 



\section{Sammanfattning}

Simuleringsdriven process- och produktutveckling har möjliggjorts tack vare utvecklingar inom numeriska beräkningar och datorernas prestandaökning. Användningen av simuleringsverktyg inom designprocessen möjliggör detaljerade utvärderingar av produktens egenskaper, vilket kan ersätta tidskrävande och dyr prototypprovning. För produkter tillverkade av tunnplåt, är det viktigt att kunna förutsäga eventuella brott både under dess tillverkning och i dess efterföljande användning. Noggranna numeriska modeller är fundamentala för att pålitliga resultat skall erhållas. Den ökande efterfrågan på fordon med låg vikt har medfört ökad användning av höghållfasta stål. Dessa stål visar ofta olika egenskaper i olika riktningar och ett mera komplext hårdnande jämfört med traditionella stål. Följaktligen efterfrågas noggranna och effektiva material- och brottmodeller som lämpar sig för dessa stål.

I denna doktorsavhandling har brottbeteendet hos de höghållfasta stålen Docol 600DP och Docol 1200M undersökts experimentellt vid olika belastningar. Resultat från dessa experiment har sedan använts för material- och brottkarakterisering. En industriell tillämpbarhet har varit viktig vid utvecklingen av de föreslagna brottkriterierna, dvs. brottkriterierna skall vara enkla att kalibrera och enkla att använda i de programvaror som industrin använder.

Detaljerade finita elementmodeller med noggranna materialmodeller har använts för att prediktera instabiliteter. Eftersom både spännings- och töjningstillstånd anses vara viktiga för materialbrott har de flesta använda brottmodellerna baserats på olika varianter av plastiskt arbete till brott. Brottet har identifierats som ett dragbrott eller skjuvbrott beroende på brottytans karaktär.

Avhandlingen består av två delar. I den första delen ges teori och bakgrund till material- och brottmodellering. Den andra delen innehåller fem vetenskapliga artiklar. 



\section{List of papers}

In this dissertation, the following papers have been included:

I. R. Larsson, O. Björklund, L. Nilsson, K. Simonsson (2011). A study of high strength steels undergoing non-linear strain paths - Experiments and modelling, Journal of Materials Processing Technology, Volume 211, No. 1, pp. $122-132$.

II. O. Björklund, R. Larsson, L. Nilsson (2013). Failure of high strength steel sheets - Experiments and modelling, Journal of Materials Processing Technology, Volume 213, No. 7, pp. 1103-1117.

III. O. Björklund, L. Nilsson (2014). Failure characteristics of a dual-phase steel sheet, Journal of Materials Processing Technology, Volume 214, No. 6, pp. 1190-1204.

IV. O. Björklund, A. Govik, L. Nilsson (2014). Prediction of fracture in a dualphase steel subjected to non-linear straining, Submitted.

V. O. Björklund, L. Nilsson (2014). Anisotropic fracture criteria for a dualphase steel, Submitted.

\section{Note}

The appended papers have been reformatted to fit the layout of the thesis.

\section{Own contribution}

The experimental programme was a joint effort by Rikard Rentmeester (formerly Larsson) and myself. In the first paper Rikard Rentmeester bore the primary responsibility but I participated in the modelling work. The fourth paper was performed in collaboration with Alexander Govik. However, I bore the primary responsibility for the fracture modelling and Alexander Govik for the forming simulations. In all other papers, I have borne primary responsibility for all parts of the work. 



\section{Contents}

Preface iii

Abstract $\quad$ V

Sammanfattning vii

$\begin{array}{ll}\text { List of papers } & \text { ix }\end{array}$

Contents $\quad$ xi

Part I - Theory and background 1

1 Introduction $\quad 3$

1.1 Steels ............................ 4

1.2 This thesis . . . . . . . . . . . . . . . 5

2 Deformation and fracture $\quad 7$

3 Failure representation $\quad 11$

4 Constitutive modelling $\quad \mathbf{1 5}$

4.1 Effective stress . . . . . . . . . . . . . . . . . . 15

4.2 Hardening . . . . . . . . . . . . . . . . . . . . . . . . . . . . 19

4.3 Strain rate sensitivity . . . . . . . . . . . . . . . . . . 24

4.4 Elastic stiffness degradation . . . . . . . . . . . . . . 25

5 Modelling instability $\quad 27$

5.1 The Marciniak and Kuczyński model . . . . . . . . . . . . . . . . . 27

5.2 Finite element model . . . . . . . . . . . . . . . . . . . . . 29

5.3 Evaluation of instability in finite element models . . . . . . . . . . . 30

6 Fracture modelling $\quad 31$

6.1 Phenomenological fracture criteria . . . . . . . . . . . . . . . 32

6.2 Anisotropic fracture criteria . . . . . . . . . . . . . . 37 
7 Mechanical experiments $\quad 41$

7.1 Pre-deformation test . . . . . . . . . . . . . . . . 41

7.2 Tensile test . . . . . . . . . . . . . . . . . . 43

7.3 Plane strain tensile test . . . . . . . . . . . . . . . . . . 43

7.4 In-plane shear test . . . . . . . . . . . . . . . . . . . . 43

7.5 Balanced biaxial test . . . . . . . . . . . . . . . . 44

7.6 Nakajima test . . . . . . . . . . . . . . . . . . . . . . 44

7.7 Exhaust bracket test . . . . . . . . . . . . . . 46

$\begin{array}{lll}8 & \text { Review of appended papers } & 47\end{array}$

9 Conclusions and discussion $\quad 51$

10 Outlook $\quad 53$

$\begin{array}{ll}\text { Bibliography } & 55\end{array}$

$\begin{array}{ll}\text { Part II - Appended papers } & 61\end{array}$

Paper I: A study of high strength steels undergoing non-linear strain paths - Experiments and modelling . . . . . . . . . . 65

Paper II: Failure of high strength steel sheets - Experiments and modelling 91

Paper III: Failure characteristics of a dual-phase steel sheet . . . . . . . 123

Paper IV: Prediction of fracture in a dual-phase steel subjected to nonlinear straining . . . . . . . . . . . . . . . . . 157

Paper V: Anisotropic fracture criteria for a dual-phase steel . . . . . . . 187 
Part I

Theory and background 



\section{Introduction}

Developments in computer-aided engineering, CAE, and the rapid growth of computational power have made simulation-driven manufacturing process and product development efficient and useful. Simulation-based design, SBD, enables a detailed evaluation of the product design with the use of finite element, FE, simulations. The opportunity to determine the product's properties at early stages of the design process reduces development time and cost without the need for physical testing. Accurate numerical models in the SBD process are of utmost interest in order to obtain trustworthy results. Furthermore, the increased demand for improved weight-to-performance ratios in order to reduce emission from vehicles has justified the use of high-strength steels. These steels often show anisotropic behaviour and a more complex hardening and fracture compared to conventional steels. Consequently, the demand for research on constitutive modelling suitable for these steels has increased.

In order to optimise sheet metal product functionality it is vital to predict possible failures, both during its forming and subsequent usage. Failure is defined as the local loss of load-carrying capacity, while fracture is defined as a material separation. Consequently, failure incorporates the term fracture but it may also be caused by other phenomena which do not include material separation e.g. material and geometrical instabilities. Macroscopic fracture has always been of great interest. As early as in the beginning of 16th century, Leonardo da Vinci explained fracture in terms of mechanical variables. He stated that the load an iron wire can carry depends on the length of the wire, as a consequence of the amount of voids within the material, see Hertzberg (1996). The longer the wire, the greater the number of voids which leads to lower load-carrying capacity. Even if material fracture has been studied for a long period of time, the underlying microscopic fracture mechanisms are hard to translate to phenomenological models. Since the underlying mechanisms need to be represented on a length scale which can be used in an FE simulation, it would be computationally expensive and hence too time consuming, to represent the fracture on a micromechanical scale.

Fracture is generally divided into ductile and brittle fracture depending on the amount of plastic deformation prior to fracture. However, the steels studied in this work are assumed to only experience a ductile type of fracture in all applications of interest. The ductile fracture is characterised by initiation, growth and coalescence of voids in the material, the loaded area is reduced, and eventually material fracture 
occurs. In sheet metal applications three failure phenomena are usually observed: (i) ductile tensile fracture, (ii) ductile shear fracture and (iii) material instability with localisation, see Lademo et al. (2009) and Figure 1. The instability with localisation is sometimes denoted as plastic failure.

An extensive amount of models for prediction of ductile fracture can be found in the literature. Two main approaches are denoted as coupled and un-coupled damage models. In the coupled damage models, material softening is coupled to the constitutive relation either by porous plasticity, cf. Gurson (1977), or by continuum damage mechanics, cf. Lemaitre (1985). In un-coupled fracture models the constitutive law are not affected before fracture. The un-coupled fracture models consider fracture to occur first when some state variable reaches a limit value. Industrial applicability has been a main focus of this study. Therefore, only un-coupled fracture models are used, since they have few material parameters and are easier to calibrate.

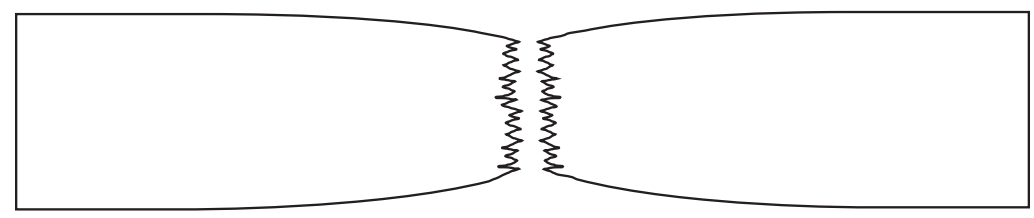

(a)

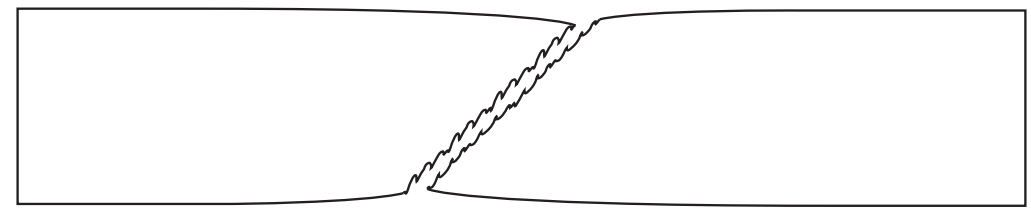

(b)

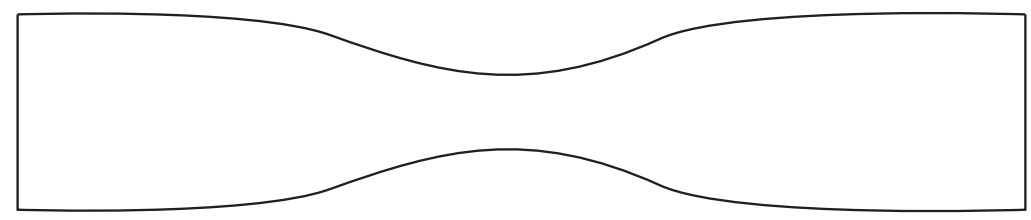

(c)

Figure 1: Failure types in sheet metals, (a) ductile tensile fracture, (b) ductile shear fracture, (c) instability with localisation.

\subsection{Steels}

The classification of different steel grades is often made from the amount and type of alloy substances. However, it is also common to classify steel according to strength, e.g. high-strength low alloy steel, HSLA, high-strength steel, HSS, ultra high-strength steel, UHSS, and advance high-strength steel, AHSS. For example steels with a yield strength between 210 and $550 \mathrm{MPa}$ are classified as HSS and 
steels with a yield strength over $550 \mathrm{MPa}$ are classified as UHSS, see Opbroek (2009). A specific steel can be part of more than one group since there is no unique division. The steels in this work, Docol 600DP and Docol 1200M where Docol is an SSAB trademark, are categorised into the two groups HSS and UHSS. Docol 600DP is an HSS with a dual-phase structure consisting of about $75 \%$ ferrite and 25\% martensite, where the two-phase microstructure is produced by heat treatment. Docol $1200 \mathrm{M}$ is a UHSS with a fully martensitic steel produced by water quenching from an elevated temperature in the austenitic range, see Olsson et al. (2006). The nominal thicknesses of the steel sheets studied were $1.48 \mathrm{~mm}$ and $1.46 \mathrm{~mm}$ for Docol 600DP and Docol 1200M, respectively. For details on the chemical composition of Docol 600DP and Docol 1200M, see Table 1.

Table 1: Chemical composition of Docol 600DP and Docol 1200M.

\begin{tabular}{ccccccccc} 
& $\mathrm{C}$ & $\mathrm{Si}$ & $\mathrm{Mn}$ & $\mathrm{P}$ & $\mathrm{S}$ & $\mathrm{Nb}$ & $\mathrm{Al}$ & $\mathrm{Fe}$ \\
& {$[\%]$} & {$[\%]$} & {$[\%]$} & {$[\%]$} & {$[\%]$} & {$[\%]$} & {$[\%]$} & {$[\%]$} \\
\hline Docol 600DP & 0.10 & 0.20 & 1.5 & 0.010 & 0.002 & - & 0.04 & balance \\
Docol 1200M & 0.11 & 0.20 & 1.6 & 0.015 & 0.002 & 0.015 & 0.04 & balance \\
\hline
\end{tabular}

\subsection{This thesis}

The work on this thesis has been carried out at the Division of Solid Mechanics, Linköping University, with financial support from the VINNOVA PFF project "Fail" and the SFS ProViking project "SuperLight Steel Structures". In addition to Linköping University also DYNAmore Nordic, Outokumpu Stainless, Saab Automobile, Scania CV, SSAB, Swerea IVF and Volvo Car Corporation took part in the projects.

In the first part of this thesis the theory and background of material and failure modelling are given. In the second part five papers are presented. 



\section{Deformation and fracture}

It is vital to understand the mechanisms that cause the deformation which eventually leads to fracture in a sheet metal component, and an overview is presented in this chapter. The topics of deformation and fracture are covered in several text books, see e.g. Hertzberg (1996). Throughout this work the following definitions have been used:

- Failure - loss of load-carrying capacity

- Fracture - material separation

Consequently, the term failure includes fracture but failure can also be caused by other structural phenomena, e.g. material and geometric instabilities. The deformation of steel can be split into elastic and inelastic parts. The elastic (reversible) deformation, which occurs at the atomic level, does not cause any permanent deformation of the material. Inelastic or plastic deformation, on the other hand, causes permanent deformation. In all large deformation applications the elastic deformation of steel is relatively small compared to the plastic deformation and the elastic response is usually assumed to be linear.

Plastic deformation occurs primarily due to two mechanisms known as slip and twinning within the crystal structure. Slip is a translation of atomic planes by interaction of shear forces. The theoretical critical shear stress needed to produce plastic deformation by slip in a perfect crystal lattice is large, since a huge number of atomic bounds need to be broken simultaneously. In physical experiments, however, significantly lower critical shear stresses are needed, cf. Dieter (1986). The concept of dislocation has been introduced in order to explain the differences between theoretical and experimental observations. Dislocations are crystallographic defects, or irregularities, within the crystal structure. Dislocations enable the slip mechanism to occur in steps, and significantly lower level of stress is consequently needed to produce plastic deformation.

The second plastic deformation mechanism, twinning, can be illustrated as a rotation around a symmetrical plane known as the twin plane. The atomic structure of a twin is a mirror image around the twin plane and a shape change occurs during the twinning deformation. Twins may occur both during deformation as mechanical twinning or during recrystallization as an annealing twin. Mechanical twins occurs mainly in metals with hexagonal close-packed, HCP, crystal structures or during rapid loading, cf. Hosford (2005). 
Plastic deformation continues until a material fracture occurs. However, often instability, i.e. strain localisation, precedes material fracture. In the ordinary tensile test of a sheet metal, two types of instability may occur: diffuse necking and localised necking, see Figure 2. Both mechanisms occur when the work hardening is no longer able to compensate for the reduction in load-carrying area. In a more general loading case, localisation can occur without a preceding diffuse necking. At plastic failure, the deformation localises into a narrow region in which further deformation takes place and where material fracture is imminent. In sheet metal forming applications, material instability due to thickness localisation is usually unaccepted and considered to be a limiting condition.

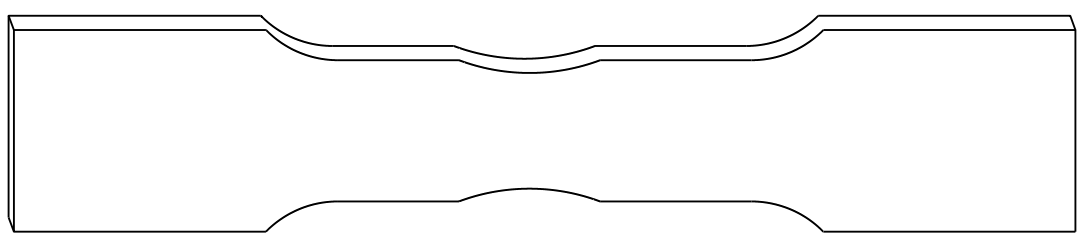

(a)

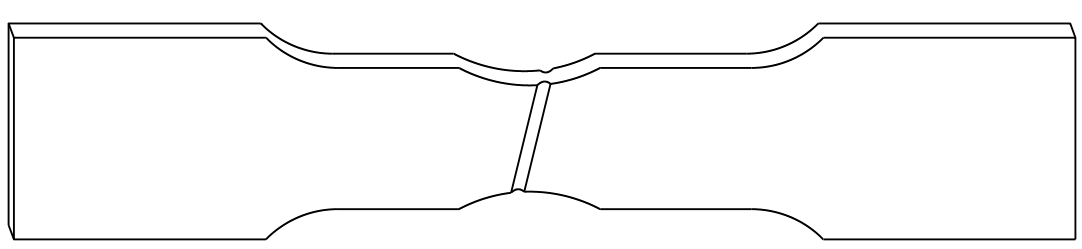

(b)

Figure 2: Instabilities in the uniaxial tensile test of a steel sheet, (a) diffuse necking and (b) localised necking.

Elastic or plastic deformations do not destroy the atomic arrangement of the steel while fracture, on the other hand, causes discontinuities within the material. These discontinuities lead to stress concentrations which increase the 'rate' of fracturing. Fracture is often divided into either brittle or ductile fracture depending on the amount of plastic deformation. Brittle fracture is the breaking of interatomic bonds without noticeable plastic deformation. These fractures occur when the local strain energy becomes larger than the energy needed to pull the atom layers apart. Brittle fracture occurs mainly in high-strength steels with poor ductility and toughness. However, even steels that have normal ductility may exhibit brittle fracture at low temperatures, in thick sections or at high strain-rates. The surface of a brittle fracture is characterised by its flat appearance and the fracture surface is almost often perpendicular to the applied load.

Ductile fracture, on the other hand, is caused by instability which is the result of extensive plastic deformation occurring in the surroundings of crystalline defects. Global deformation in a ductile fracture may be either large or small, depending on the density of the defects. The ductile fracture process is characterised by initiation, growth and coalescence of voids in the material, the loaded area is reduced, 
and eventually material fracture occurs. The ductile fracture properties are determined from the interaction of stress and strain fields acting on the microstructure, cf. Garrison Jr and Moody (1987). The fracture surface is characterised by the presence of dimples, see Figure 3, whose shapes are influenced by the direction of the deformation. The steels in this study are believed to fracture due to ductile fracture in all applications of interest.

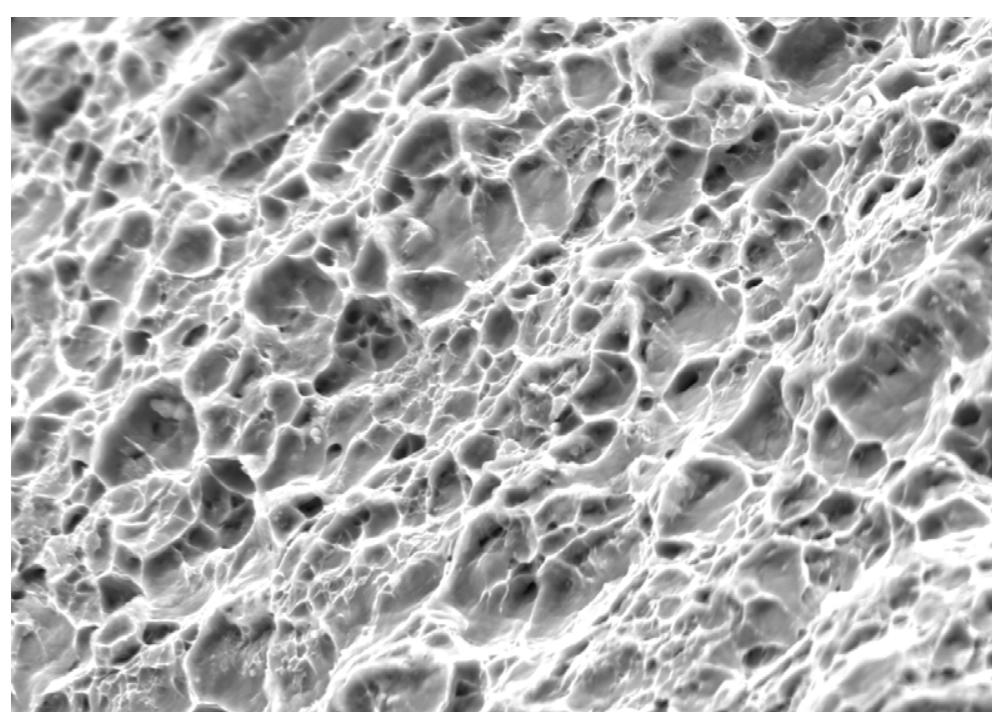

Figure 3: A scanning electron microscope picture of a fracture surface in Docol 600DP at 1000 times magnification.

The process of ductile fracture is often divided into two sub-categories denoted ductile tensile fracture and ductile shear fracture. In a ductile tensile fracture, the dimples usually show a circular appearance while in a shear dominated ductile fracture the dimples exhibit an elongated elliptical shape, see Metals Handbook (1974). Furthermore, the ductile shear fracture surface consists of fine, closely-spaced dimples which are much wider than they are deep, see Garrison Jr and Moody (1987). In the ductile tensile fracture the coalescence of voids occurs by internal necking of the ligaments between the voids, see Hosford (2005) and Figure 4.
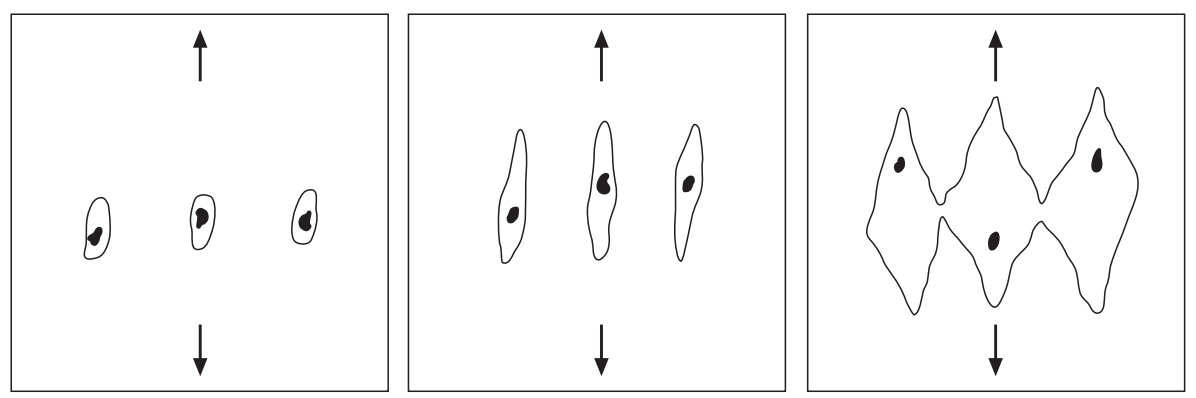

Figure 4: Schematic illustration of the initiation, growth and coalescence of voids during tensile fracture. 
The ductile shear fracture can be caused either by extensive slip on the activated slip planes, see Dieter (1986), or as a result of void nucleation in slip bands. Both these mechanisms are favoured by shear stresses. When voids nucleate in slip bands, the loaded area is reduced so that plastic flow localises there. Continued shear increases the area of voids until separation occurs. Furthermore, as stated by Teirlinck et al. (1988) "Voids which extend in shear need not increase in volume, so shear fracture is less pressure-dependent than ductile fracture, though it remains more pressure-dependent than purely-plastic failure". A schematic view of void growth and coalescence during ductile shear fracture is shown in Figure 5.
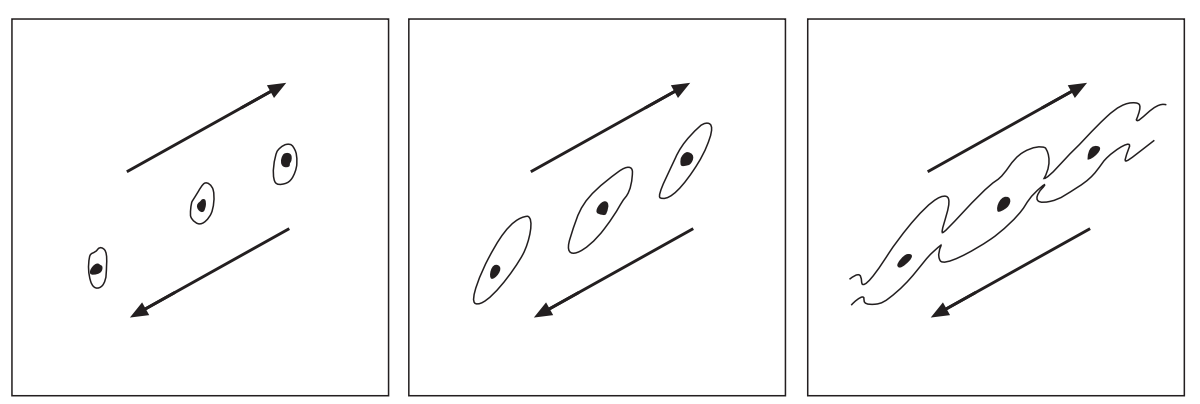

Figure 5: Schematic illustration of the initiation, growth and coalescence of voids during shear fracture.

By examining the fracture surface under a microscope, it is most often noted that different fracture types are present in different areas of the specimen, cf. Li et al. (2011). For example, in the tensile test of a round specimen, the failure process is initiated by instability followed by a ductile tensile fracture in the centre of the specimen before finally complete separation occurs by shear, cf. Anderson (2005). 


\section{Failure representation}

The forming limit diagram, FLD, has been a popular means for describeing the formability of a sheet metal ever since it was presented by Keeler and Backofen (1963) and Goodwin (1968). The classical forming limit curve, FLC, is shown in the major and minor principal strain space and it is derived either from experimental results or from analytical models. However, the FLC is a useful locus of failure only for proportional strain paths since it depends on strain history, cf. Hosford and Cadell (1993). In order to address the problem of path dependency in strainbased FLCs, stress-based FLCs have been proposed, cf. Stoughton (2000), which have been argued to be independent of strain path. There has, however, been no experimental validation of the stress-based FLC concept since generally it is difficult to experimentally determine the exact stress state in a sheet. The stress state is most often evaluated from the strain state using constitutive assumptions. By using an isotropic hardening assumption, a path independent stress-based FLC can be obtained, cf. Aretz et al. (2011). However, if a more complex hardening is used, i.e. kinematic, mixed or distortional hardening, the path independency is not ensured. Thus, unless isotropic hardening applies, path independency of the FLD is generally not ensured, cf. Yoshida et al. (2007).

The representation of failure limits in other types of diagrams has gained popularity. The effective plastic strain at failure is often presented as a function of different stress measures such as stress triaxiality and Lode parameter. In this chapter a short description of some common stress measures and variables is given. The first invariant, $I_{1}$, of the Cauchy stress, $\boldsymbol{\sigma}$, is proportional to the hydrostatic pressure, $p$, and the mean stress, $\sigma_{m}$, such that

$$
I_{1}=\operatorname{tr}(\boldsymbol{\sigma})=\sigma_{1}+\sigma_{2}+\sigma_{3}=3 \sigma_{m}=-3 p
$$

where $\sigma_{1}, \sigma_{2}$ and $\sigma_{3}$ are the principal stresses. The deviatoric stress tensor is defined as

$$
\boldsymbol{s}=\boldsymbol{\sigma}-\frac{1}{3} I_{1} \boldsymbol{I}
$$

where $\boldsymbol{I}$ is the unit tensor. From the deviatoric stress tensor, the second and third deviatoric invariants, $J_{2}$ and $J_{3}$ are defined as

$$
\begin{aligned}
& J_{2}=\frac{1}{2} s: s=\frac{1}{2} \operatorname{tr}\left(s^{2}\right) \\
& J_{3}=\operatorname{det}(s)=\frac{1}{3} \operatorname{tr}\left(\boldsymbol{s}^{3}\right)
\end{aligned}
$$


The second deviatoric stress invariant is related to the von Mises effective stress, $\bar{\sigma}_{v M}=\sqrt{3 J_{2}}$. By the use of the first invariant of the Cauchy stress and the second and third of the deviatoric stress invariants, the stress state can alternatively be defined by the cylindrical coordinates

$$
\xi=\frac{1}{\sqrt{3}} I_{1}, \quad \rho=\sqrt{2 J_{2}}, \quad \theta=\frac{1}{3} \arccos \left(\frac{\sqrt{27} J_{3}}{2 J_{2}^{3 / 2}}\right)
$$

The two different coordinate systems are shown in Figure 6(a), where the $\xi$-axis is aligned with the hydrostatic axis $\left(\sigma_{1}=\sigma_{2}=\sigma_{3}\right)$, the $\rho$-axis is directed from $O^{\prime}$ in the direction of the first principal stress, $\sigma_{1}$, in the $\pi$-plane, and the $\theta$-coordinate is the angle between the $\rho$-axis and the vector from $O^{\prime}$ to the current deviatoric stress point $B$, cf. also Figure 6(b).

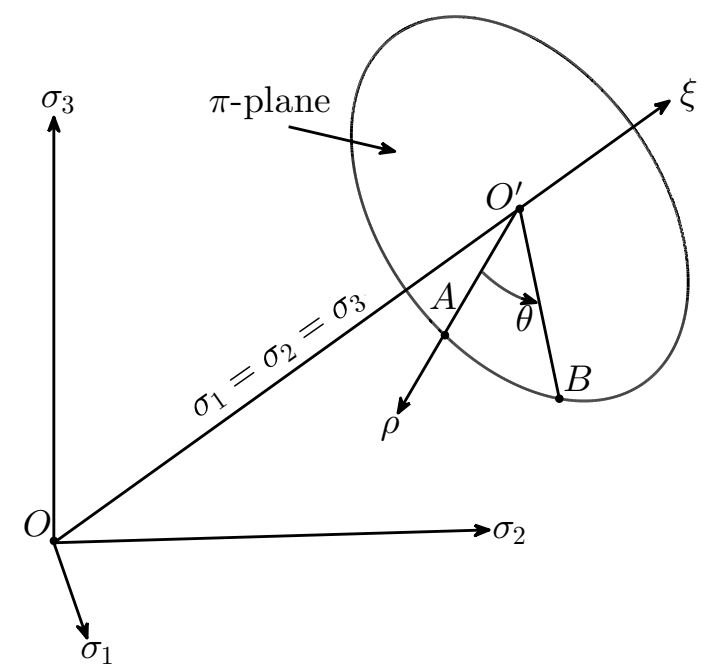

(a)

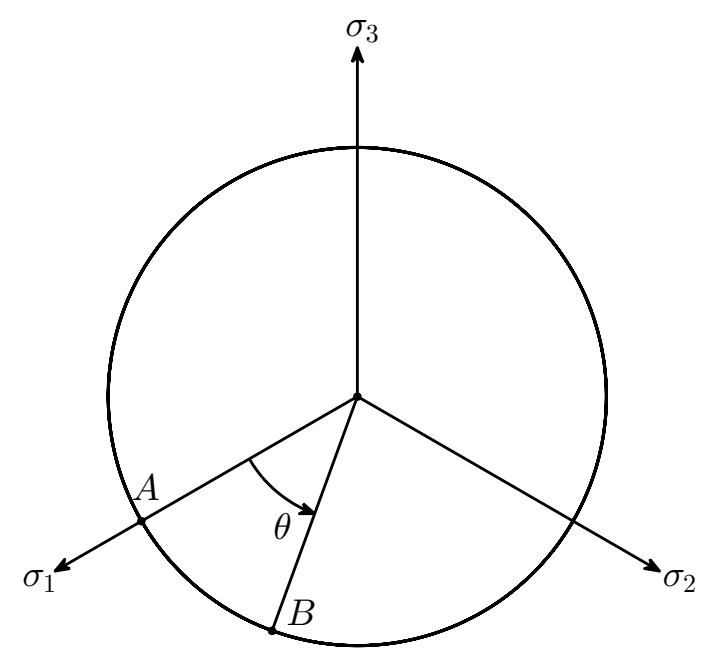

(b)

Figure 6: The Cartesian and cylindrical coordinate systems in (a) the 3D space and (b) represented in the $\pi$-plane.

The cylindrical coordinates $(\xi, \rho, \theta)$ are often referred to as the Haigh-Westergaard coordinates. A stress state can now be expressed either in the Cartesian principal stress coordinate system, $\left(\sigma_{1}, \sigma_{2}, \sigma_{3}\right)$, or in the cylindrical coordinate system, $(\xi$, $\rho, \theta)$.

$$
\left[\begin{array}{l}
\sigma_{1} \\
\sigma_{2} \\
\sigma_{3}
\end{array}\right]=\frac{\xi}{\sqrt{3}}\left[\begin{array}{l}
1 \\
1 \\
1
\end{array}\right]+\sqrt{\frac{2}{3}} \rho\left[\begin{array}{c}
\cos (\theta) \\
\cos (\theta-2 \pi / 3) \\
\cos (\theta+2 \pi / 3)
\end{array}\right]
$$

The angle $\theta$ is sometimes referred as the Lode angle due to its relation to the Lode parameter, see Lode (1926),

$$
\mu=\frac{2 \sigma_{2}-\sigma_{1}-\sigma_{3}}{\sigma_{1}-\sigma_{3}}
$$


where the principal stresses are ordered so that $\sigma_{1} \geq \sigma_{2} \geq \sigma_{3}$. The relation between the Lode parameter, $\mu$, and the Lode angle, $\theta$, can be found from Equations (5) and (6)

$$
\mu=\frac{3 \tan \theta-\sqrt{3}}{\sqrt{3}+\tan \theta}
$$

where $\theta$ needs to be between $0^{\circ}$ and $60^{\circ}$ in order to satisfy the order of the principal stresses. The Lode parameter thus ranges from -1 to 1 . Another important measure is the ratio between the hydrostatic pressure and the von Mises effective stress. This is known as the stress triaxiality and is defined as

$$
\eta=-\frac{p}{\bar{\sigma}_{v M}}
$$

For a plane stress case, the stress triaxiality ranges from biaxial compression to biaxial tension and has values from $-2 / 3$ to $2 / 3$. Furthermore, a one to one relation between the Lode angle and the stress triaxiality can be obtained from Equation (5) in the case of plane stress, as shown in Figure 7.

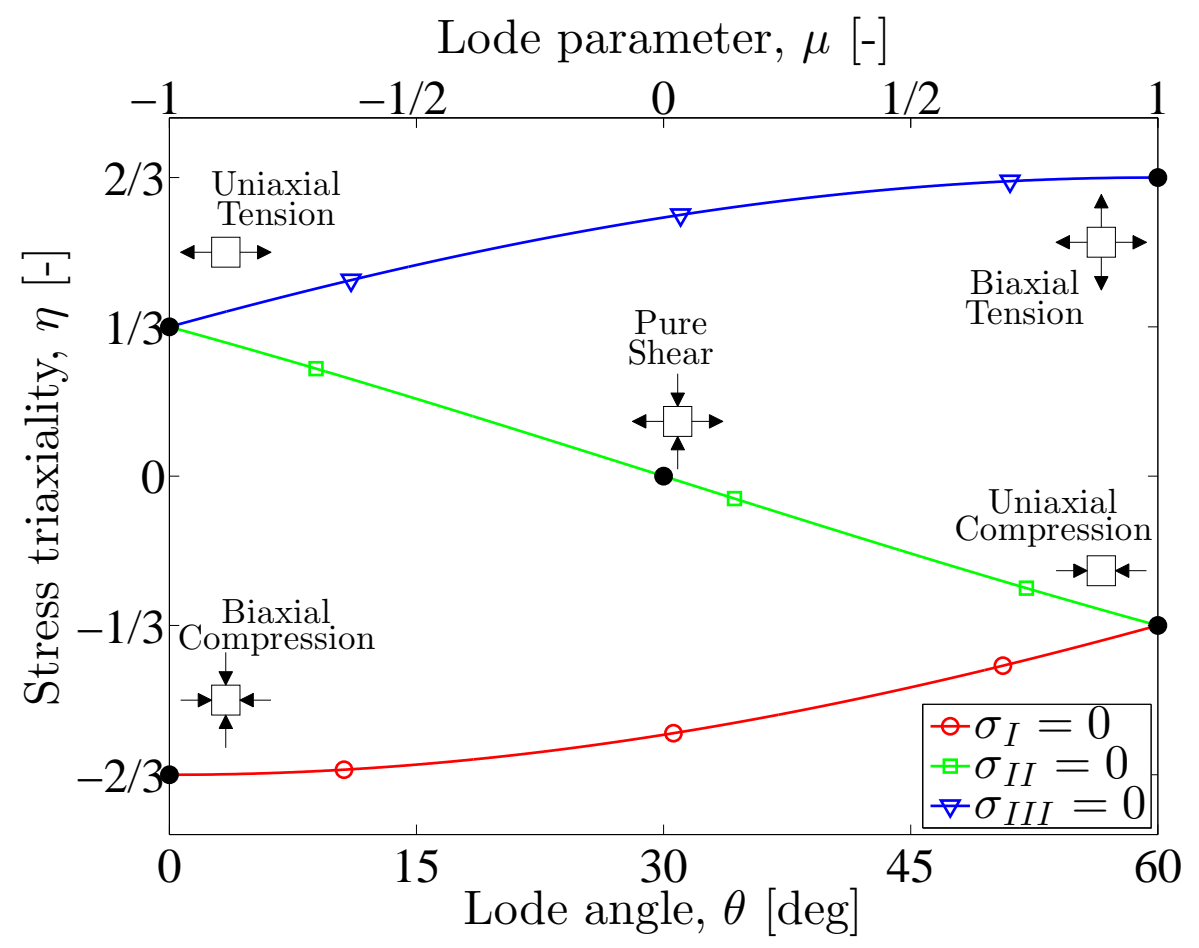

Figure 7: Relationship between stress triaxiality, Lode angle and Lode parameter in plane stress. 



\section{Constitutive modelling}

Since the industrial applications in sheet metal forming processes and vehicle collisions involve large deformations and large displacements of the material, it is necessary to formulate the constitutive equations accordingly. By using a co-rotational material frame, cf. Belytschko et al. (2000), large deformations and large displacements can be accounted for. Henceforth, all subsequent relations are related to a co-rotated configuration. In cases of small elastic deformations, a hypo-elastic stress update can be assumed, cf. Needleman (1985) i.e.

$$
\dot{\boldsymbol{\sigma}}=\boldsymbol{C}: \boldsymbol{D}^{e}=\boldsymbol{C}:\left(\boldsymbol{D}-\boldsymbol{D}^{p}\right)
$$

where $\boldsymbol{C}$ is the fourth order elastic stiffness tensor, which in this work is assumed to be isotropic. $\boldsymbol{D}$ is the rate of deformation tensor, which is assumed to follow an additive decomposition, i.e. $\boldsymbol{D}=\boldsymbol{D}^{e}+\boldsymbol{D}^{p}$. Plastic deformations will not occur as long as the stress state is in the elastic regime as determined by the yield function

$$
f=\bar{\sigma}-\sigma_{f}
$$

where $\bar{\sigma}$ and $\sigma_{f}$ are the effective and flow stresses, respectively. The yield function determines the elastic limit of the material and the hypersurface, $f=0$, is denoted as the yield surface. As long as $f<0$ no plastic deformation occurs and when $f=0$, the material may either experience plastic flow, if $\dot{f}=0$, or elastic unloading, if $\dot{f}<0$. The plastic part of the rate of deformation tensor will be determined from the plastic potential, $g$, according to

$$
\boldsymbol{D}^{p}=\dot{\lambda} \frac{\partial g}{\partial \boldsymbol{\sigma}}
$$

where $\dot{\lambda}$ is the plastic multiplier and the gradient of $g$ determines the direction of plastic flow. In an associated flow assumption, the plastic flow coincides with the normal of the yield surface and in this case the plastic potential and the yield function coincide, i.e. $g=f$. Associated plastic flow has been assumed throughout this work.

\subsection{Effective stress}

In a uniaxial stress state, the onset of plastic yielding is quite simple to identify. However, for a more complex loading situation the effect of all stresses needs to 
be considered. The effective stress is a measure of stress intensity. Many effective stress expressions have been presented over the years. For an isotropic material behaviour the von Mises, also called $J_{2}$-flow, theory is often used. The von Mises yield function, $\bar{\sigma}_{v M}$, is a quadratic homogenous function, however in order to improve the prediction of the material behaviour non-quadratic yield functions have been proposed, see e.g. Hershey (1954). The non-quadratic isotropic yield function according to Hershey (1954) is

$$
\bar{\sigma}_{H}(\boldsymbol{\sigma})=\left[\frac{1}{2}\left(\left|\sigma_{1}-\sigma_{2}\right|^{a}+\left|\sigma_{2}-\sigma_{3}\right|^{a}+\left|\sigma_{3}-\sigma_{1}\right|^{a}\right)\right]^{1 / a}
$$

where $\sigma_{1}, \sigma_{2}$ and $\sigma_{3}$ are the principal stresses and $a$ is the yield function exponent. Effective stresses according to von Mises and Tresca can be obtained as special cases of Equation 12, i.e. in the von Mises case $a=2$ or 4 and in the Tresca case $a=1$ or $\infty$. It is generally recommended to set the yield function exponent $a$ to 6 or 8 for body-centred cubic, BCC, and face-centred cubic, FCC, materials, respectively, see e.g. Hosford (1993). However, for dual-phase steels no such recommendation has been found, cf. Aretz et al. (2007). By expressing the principal stresses in HaighWestergaard coordinates and using the Lode parameter a relationship between the von Mises and Hershey effective stresses can be found, cf. Gruben et al. (2013)

$$
\bar{\sigma}_{v M}=\frac{\sqrt{3+\mu^{2}}}{\left[\frac{(1-\mu)^{a}+(1+\mu)^{a}+2^{a}}{2}\right]^{1 / a}} \bar{\sigma}_{H}
$$

where $\mu$ is the Lode parameter, see Chapter 3. The effective stress according to Hershey (1954) was used in Paper III.

\section{Plastic anisotropy}

The von Mises and Hershey effective stresses can only account for isotropic behaviour. However, sheet metals are generally roll formed, which leads to different properties in different material directions. Consequently, an effective stress function considering this anisotropy is needed. Even if anisotropic effective stresses for full stress states were presented several decades ago, see e.g. Hill (1948), a limitation to plane stress states is often made in sheet metal applications. The rolling direction, $\mathrm{RD}$, transversal direction, TD and normal direction, ND, are used to describe the axes of orthotropy in sheet metals. Anisotropy can occur in the elastic material stiffness in the plastic flow and in the yield stress. However, anisotropy during elastic loading is not considered in this work. Anisotropy in plastic flow can be described by the Lankford parameter, $R$, see e.g. Hosford and Cadell (1993), or by the plastic strain ratio, $k$. In uniaxial tension the Lankford parameters and plastic strain ratios are defined as

$$
R_{\phi}=\frac{\mathrm{d} \varepsilon_{T}^{p}}{\mathrm{~d} \varepsilon_{N}^{p}}
$$


and

$$
k_{\phi}=\frac{\mathrm{d} \varepsilon_{T}^{p}}{\mathrm{~d} \varepsilon_{L}^{p}}=\frac{-R_{\phi}}{R_{\phi}+1}
$$

where the subindices on the logarithmic plastic strain increments indicate the transversal, $T$, normal, $N$, and longitudinal, $L$, directions of the tensile test specimen, respectively. The anisotropy in yield stress is given by

$$
r_{\phi}=\frac{\sigma_{\phi}^{y}}{\sigma_{r e f}}
$$

where $\sigma_{\phi}^{y}$ is the yield stress in the $\phi$ direction and $\sigma_{\text {ref }}$ is a reference yield stress. Equations (14), (15) and (16) are expressed for uniaxial tensile test cases but similar equations can be defined for the balanced biaxial test

$$
R_{b}=k_{b}=\frac{\mathrm{d} \varepsilon_{T D}^{p}}{\mathrm{~d} \varepsilon_{R D}^{p}}
$$

and

$$
r_{b}=\frac{\sigma_{b}^{y}}{\sigma_{r e f}}
$$

where the subscript $b$ denotes balance biaxial test. The interpretation of the plastic strain ratios, $k$, and the yield stress ratios, $r$, is shown in Figure 8.

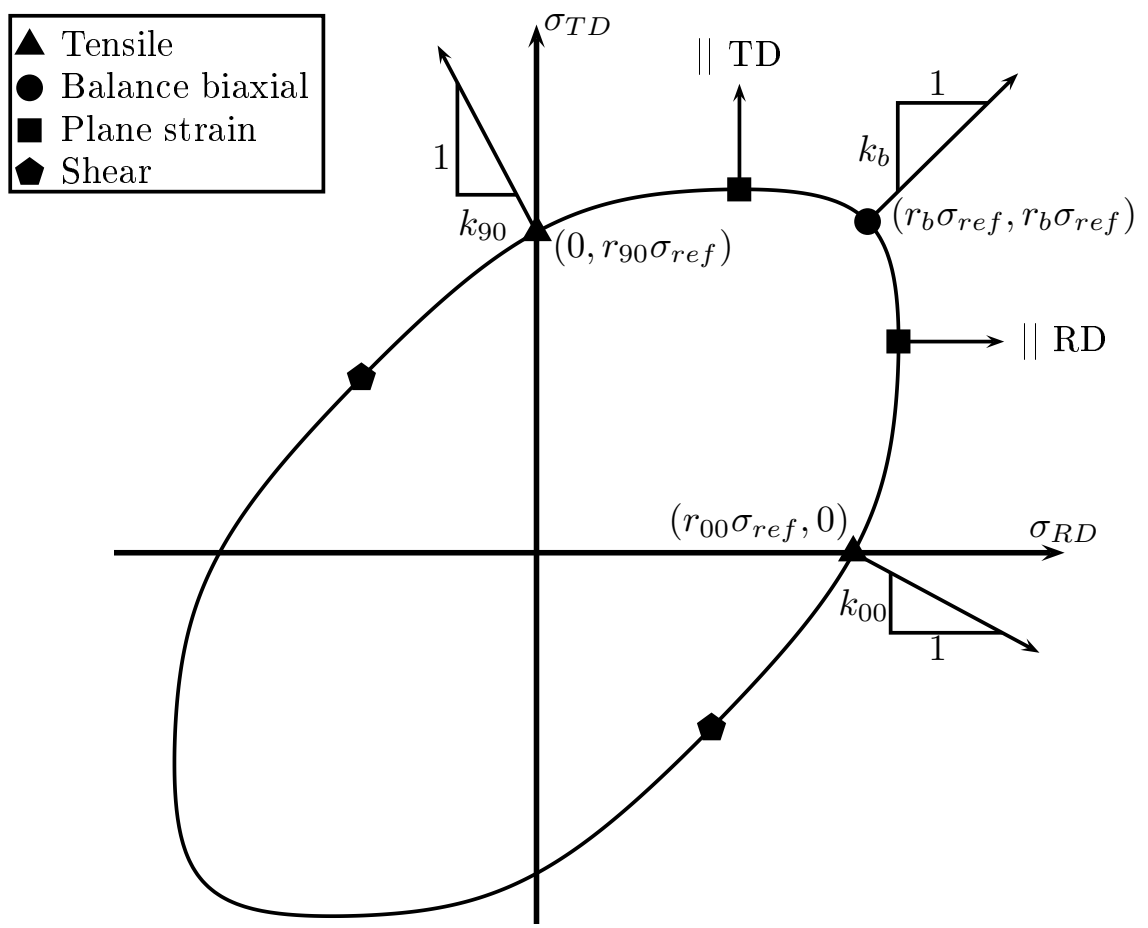

Figure 8: Yield locus in a plane stress case with $\tau_{R T}=0$. 
Anisotropic yield functions have been presented by numerous authors and several overviews are available, see e.g. Banabic et al. (2010). In all papers except Paper III, the effective stress denoted as Yld2003, see Aretz (2005), has been used.

$$
\begin{aligned}
& \bar{\sigma}(\boldsymbol{\Sigma})=\left[\frac{1}{2}\left(\left|\Delta_{1}^{\prime}\right|^{a}+\left|\Delta_{2}^{\prime}\right|^{a}+\left|\Delta_{1}^{\prime \prime}-\Delta_{2}^{\prime \prime}\right|^{a}\right)\right]^{1 / a} \\
& \left.\begin{array}{c}
\Delta_{1}^{\prime} \\
\Delta_{2}^{\prime}
\end{array}\right\}=\frac{A_{8} \sigma_{11}+A_{1} \sigma_{22}}{2} \pm \sqrt{\left(\frac{A_{2} \sigma_{11}-A_{3} \sigma_{22}}{2}\right)^{2}+A_{4}^{2} \sigma_{12} \sigma_{21}} \\
& \left.\begin{array}{c}
\Delta_{1}^{\prime \prime} \\
\Delta_{2}^{\prime \prime}
\end{array}\right\}=\frac{\sigma_{11}+\sigma_{22}}{2} \pm \sqrt{\left(\frac{A_{5} \sigma_{11}-A_{6} \sigma_{22}}{2}\right)^{2}+A_{7}^{2} \sigma_{12} \sigma_{21}}
\end{aligned}
$$

where $A_{1}, \ldots, A_{8}$, and $a$ are material constants. The model was originally derived for a plane stress case, where the 11-direction and 22-direction correspond to the $\mathrm{RD}$ and TD, respectively. However, a regularisation that enables a $C^{0}$ continuous thickness has been made. Thus the through-thickness normal stress, $\sigma_{N D}$, has been included in the effective stress such that, $\sigma_{11}:=\sigma_{R D}-\sigma_{N D}$ and $\sigma_{22}:=\sigma_{T D}-\sigma_{N D}$. A comparison between different effective stresses for a plane stress case is shown in Figures 9 and 10.

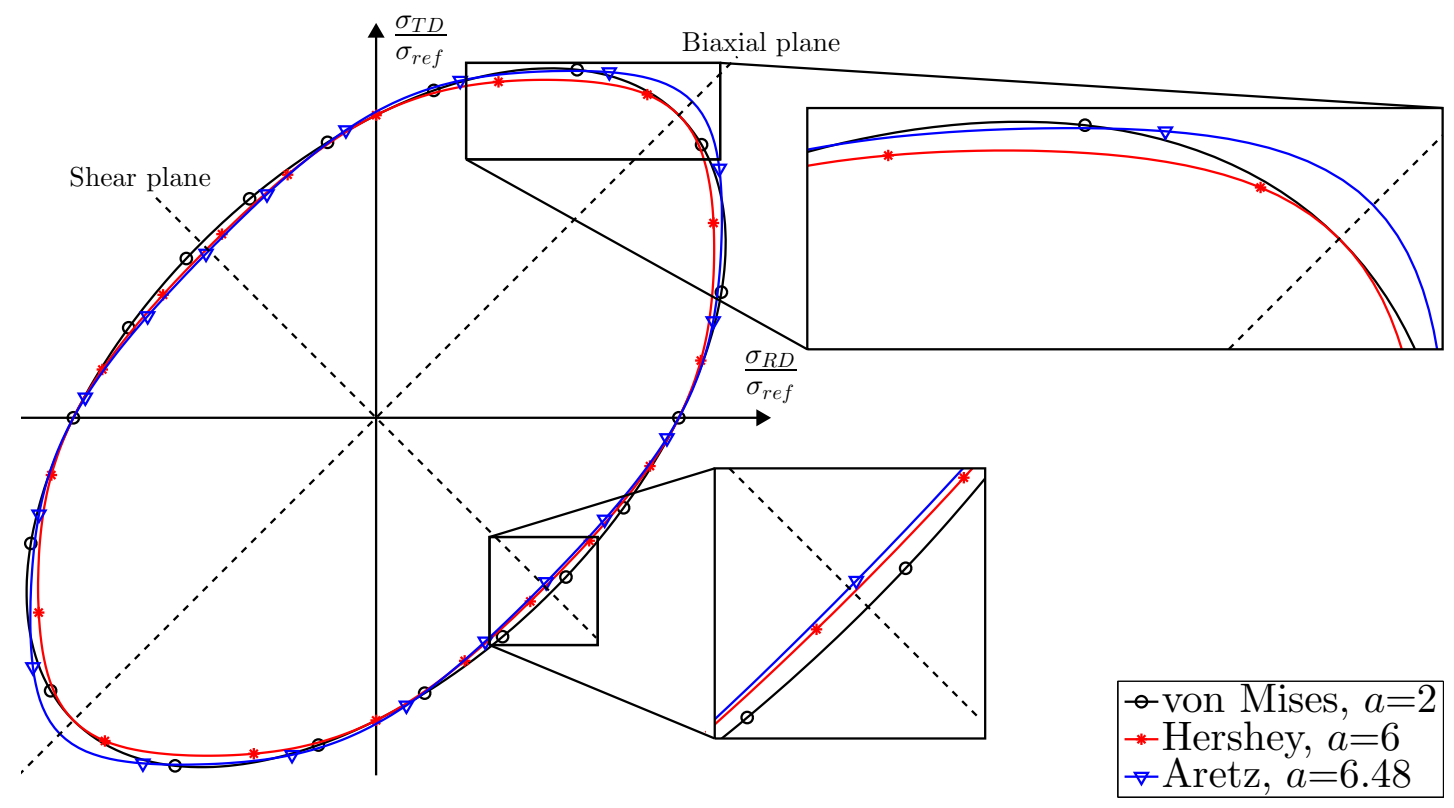

Figure 9: Yield loci in a plane stress assumption, $R D$ and TD indicate the rolling and transversal directions, respectively. 


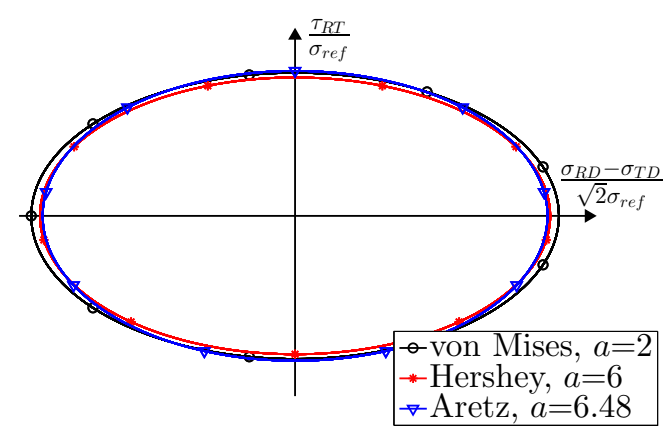

(a)

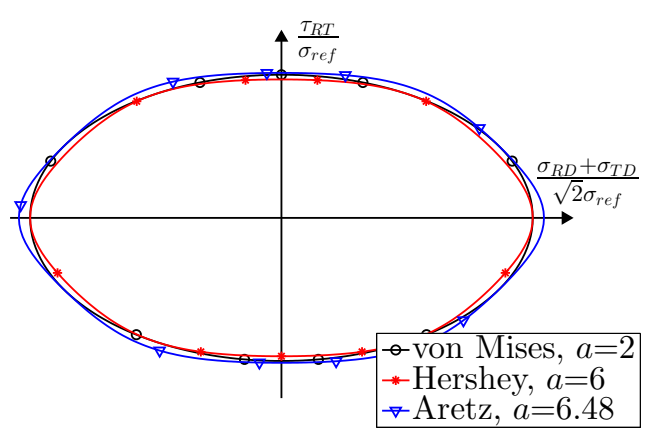

(b)

Figure 10: Yield loci in different planes. $R D$ and TD indicate the rolling and transversal directions, respectively, and the index $R T$ refers to the in-plane shear component. (a) shear plane and (b) biaxial plane.

\subsection{Hardening}

Most metals exhibit positive plastic strain hardening, i.e. the yield strength increases when the material is subjected to plastic deformation. This increase in yield strength occurs due to creation and movements of dislocations within the crystal structure. Models for predicting the yield strength based on dislocation theory have been proposed, see e.g. Bergström et al. (2010). However, in this work only phenomenological models have been used to predict hardening behaviour. The non-distortional hardening is often divided into isotropic, kinematic or mixed hardening, see Figure 11.

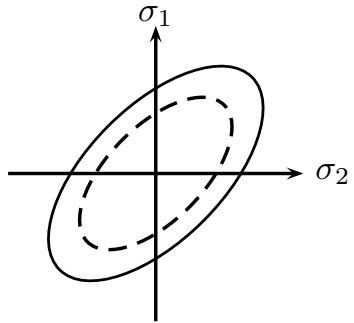

(a)

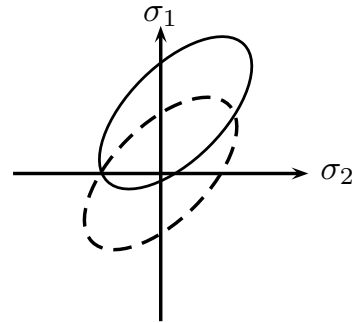

(b)

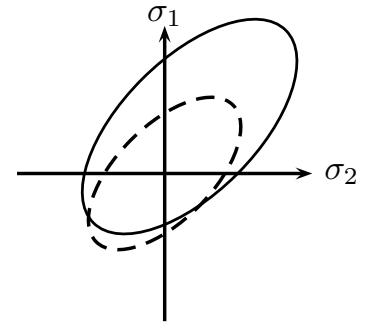

(c)

Figure 11: Different types of hardening: (a) isotropic, (b) kinematic and (c) mixed.

\section{Isotropic hardening}

Isotropic hardening can be illustrated as a uniform expansion of the yield surface, see Figure 11(a). The stress and strain responses can be influenced by several mechanical parameters such as plastic strain, plastic strain-rate and temperature, see e.g. Johnson and Cook (1983). However, in this work only the effective plastic strain and strain rate have been considered. The strain rate sensitivity will be 
treated separately in Section 4.3. The flow stress is here only described as a function of the equivalent plastic strain $\bar{\varepsilon}^{p}$. The tensile test is often used to describe plastic hardening up to diffuse necking, after which an extrapolation or inverse modelling is needed. Many analytic expressions have been proposed in the literature and a few examples are given below

$$
\sigma_{f}\left(\bar{\varepsilon}^{p}\right)= \begin{cases}\sigma_{0}+K\left(\bar{\varepsilon}^{p}\right)^{n} & \text { Hollomon (1945) } \\ \sigma_{0}+Q\left(1-e^{-C \bar{\varepsilon}^{p}}\right) & \text { Voce (1948) } \\ K\left(\varepsilon_{0}+\bar{\varepsilon}^{p}\right)^{n} & \text { Swift (1952) } \\ K\left(\varepsilon_{0}+\bar{\varepsilon}^{p}\right)^{n}-P & \text { Ghosh and Backofen (1973) } \\ \sigma_{0}+Q\left(1-e^{-C\left(\bar{\varepsilon}^{p}\right)^{n}}\right) & \text { Hockett and Sherby (1975) }\end{cases}
$$

It is also common to use the experimentally-obtained stress and plastic strain data directly. As illustrated in Figure 12, all five hardening laws predict the hardening up to diffuse necking with reasonable accuracy. However, for strain states beyond diffuse necking, clear deviations between the models are noted. By using complementing mechanical experiments, cf. Sigvant et al. (2009), or inverse modelling, cf. Tarigopula et al. (2008), plastic hardening can also be found beyond the point of diffuse necking.

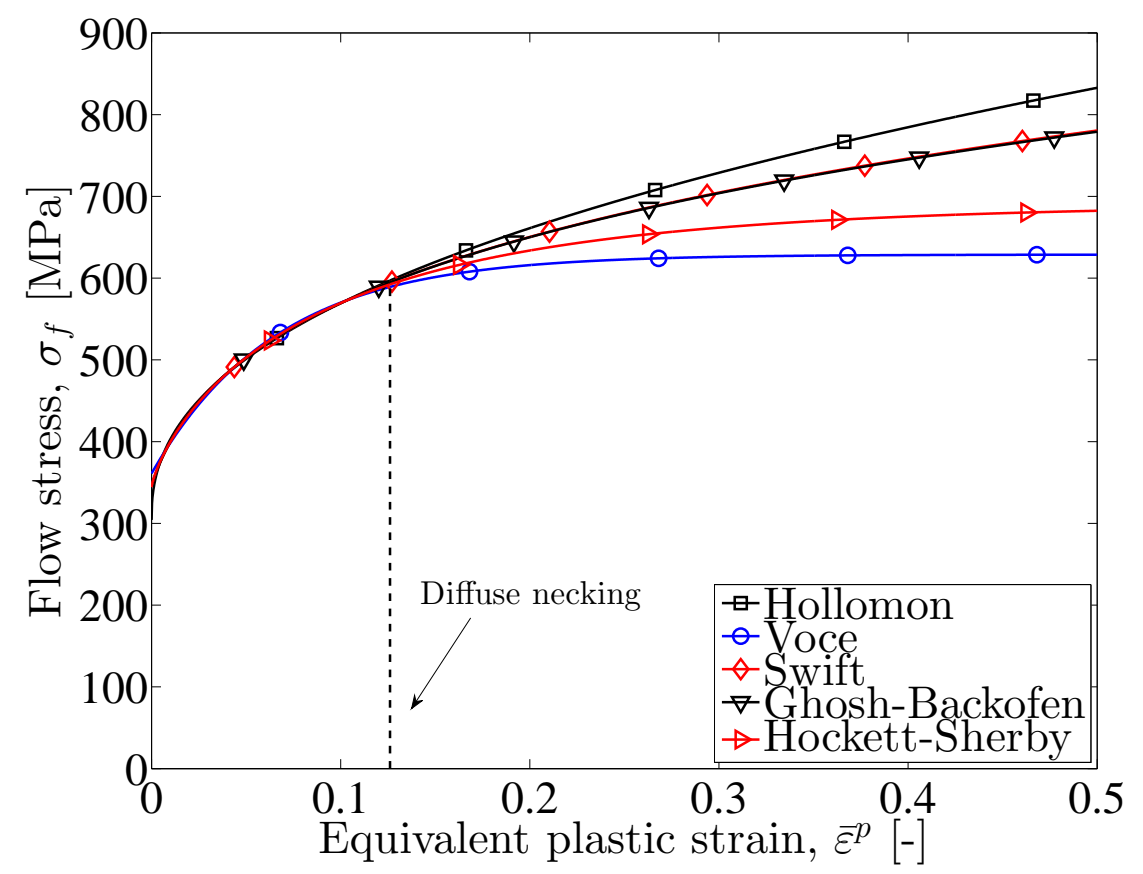

Figure 12: Different hardening laws calibrated to the tensile test up to diffuse necking. 
In this work, an extended Voce law is fitted to plastic hardening data from tensile tests up to diffuse necking. After diffuse necking an extrapolation using the Hollomon law was carried out by inverse modelling of a shear test. The analytic hardening function can then be expressed as

$$
\sigma_{f}\left(\bar{\varepsilon}^{p}\right)= \begin{cases}\sigma_{0}+\sum_{i=1}^{2} Q_{R i}\left(1-e^{-C_{R i} \bar{\varepsilon}^{p}}\right) & \bar{\varepsilon}^{p} \leq \varepsilon^{t} \\ A+B\left(\bar{\varepsilon}^{p}\right)^{C} & \bar{\varepsilon}^{p}>\varepsilon^{t}\end{cases}
$$

where $\sigma_{0}, Q_{R i}, C_{R i}, A, B$ and $C$ are material parameters and $\varepsilon^{t}$ the strain at which a transition is made from the extended Voce to Hollomon hardening. The requirements of a smooth curve, i.e. a $C^{1}$ transition between the Voce and Hollomon expressions, and the introduction of the stress at $100 \%$ plastic strain, $\sigma_{100}^{\prime}$, make it possible to determine the constants $A, B$ and $C$ by solving the following nonlinear equation system

$$
\left\{\begin{array}{l}
A+B\left(\varepsilon^{t}\right)^{C}=\sigma_{0}+\sum_{i=1}^{2} Q_{R i}\left(1-e^{-C_{R i} \varepsilon^{t}}\right) \\
C B\left(\varepsilon^{t}\right)^{C-1}=\sum_{i=1}^{2} C_{R i} Q_{R i} e^{-C_{R i} \varepsilon^{t}} \\
A+B=\sigma_{100}^{\prime}
\end{array}\right.
$$

\section{Kinematic hardening}

Plastic deformation may also introduce anisotropic behaviour of the material as, for example, manifested by the Bauschinger effect, which is the phenomenon of early re-yielding in the case of reverse loading. Also other effects such as transient behaviour, work-hardening stagnation and permanent softening may occur during revers loading, see e.g. Yoshida and Uemori (2003) and Figure 13. For the modelling of these effects it is useful to introduce a kinematic hardening model. The kinematic plastic hardening enables the yield surface to move in the stress space, see Figure 11(b). In cyclic loading, kinematic hardening has a crucial effect on the stress response. Therefore in applications that involve one or more cycles of bending-unbending, as for example in sheet metal forming, it is important to consider kinematic hardening, see e.g. Eggertsen and Mattiasson (2009).

The motion of the yield surface origin is described by the backstress tensor, $\boldsymbol{\alpha}$. The related reduced stress tensor, $\boldsymbol{\Sigma}=\boldsymbol{\sigma}-\boldsymbol{\alpha}$, replaces the Cauchy stress tensor, $\boldsymbol{\sigma}$, in the effective stress function, $\bar{\sigma}=\bar{\sigma}(\boldsymbol{\sigma}-\boldsymbol{\alpha})$. An interpretation can be seen in Figure 14 . 


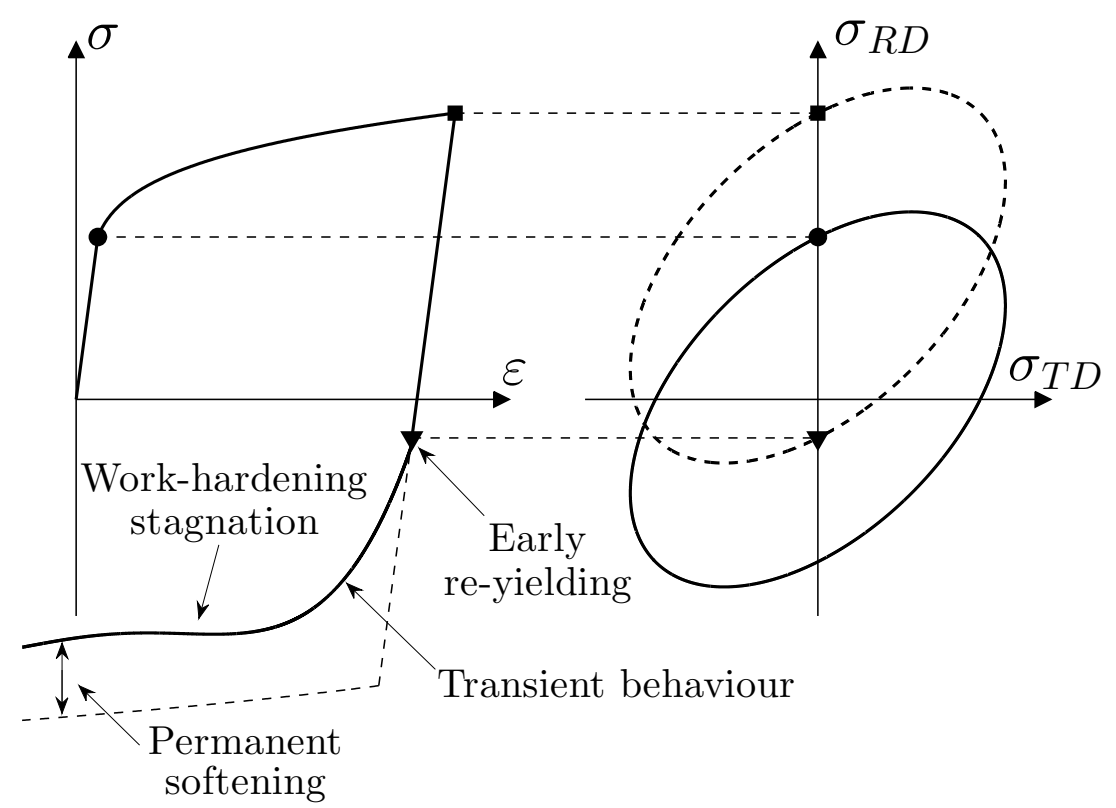

Figure 13: Illustration of the Bauschinger effect and work-hardening stagnation.

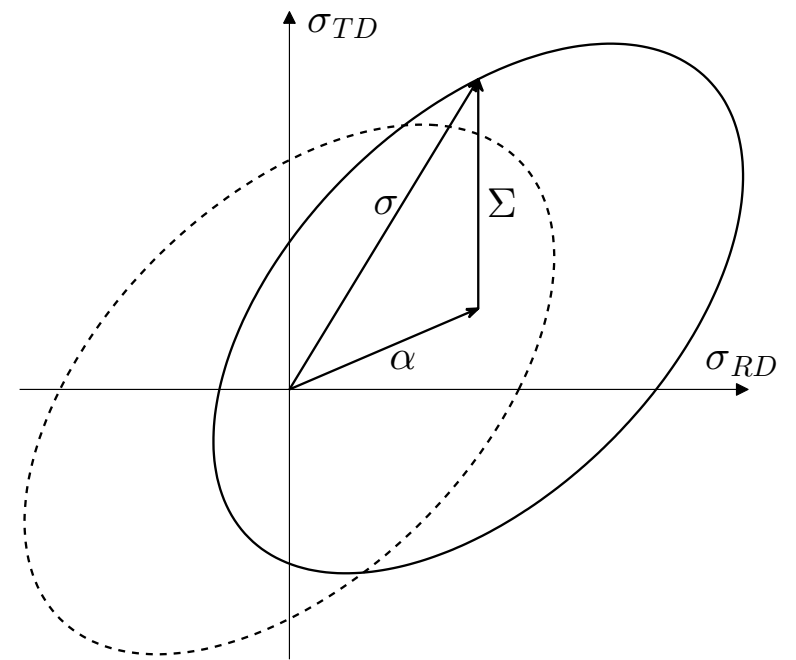

Figure 14: Interpretation of the reduced, $\boldsymbol{\Sigma}$, the backstress, $\boldsymbol{\alpha}$, and the Cauchy stress, $\boldsymbol{\sigma}$.

Several models for predicting the evolution of the backstress tensor have been presented, see e.g. Chaboche (2008). In this work the evolution of the backstress tensor has been described using the model presented by Frederick and Armstrong (2007), normally referred to as the Armstrong-Frederick law. The ArmstrongFrederick law may, in a manner similar to the Voce hardening law, be extended to several terms. During this work it was extended into a two-component law described as

$$
\dot{\boldsymbol{\alpha}}=\sum_{i=1}^{2} \dot{\boldsymbol{\alpha}}_{i}=\sum_{i=1}^{2} C_{X i}\left(Q_{X i} \frac{\boldsymbol{\Sigma}}{\bar{\sigma}}-\boldsymbol{\alpha}_{i}\right) \dot{\bar{\varepsilon}}^{p}
$$

where $Q_{X i}$ and $C_{X i}$ are material constants. Kinematic hardening in the extended 
Armstrong-Frederick law can describe the Bauschinger effect and transient behaviour. However, it is unable to describe permanent softening and work-hardening stagnation. By introducing an additional bounding yield surface, Geng and Wagoner (2002) presented a model able to predict permanent softening. Work-hardening stagnation is a phenomenon mostly found in mild steel and models to address this effect have been presented by e.g. Yoshida and Uemori (2002).

\section{Mixed hardening}

A combination of isotropic and kinematic hardening has been used in all appended papers except Paper III, in which a purely isotropic hardening was used. When subjected to a mixed hardening, the yield surface may both expand and move, see Figure 11(c). In the special case of uniaxial tension in the $\phi$-direction, the only non-zero components in the reduced stress, backstress, and Cauchy stress tensors will be $\Sigma_{\phi}, \alpha_{\phi}$, and $\sigma_{\phi}$, respectively. The evolution of the backstress can then be expressed as

$$
\alpha_{\phi}\left(\bar{\varepsilon}^{p}\right)=r_{\phi} \sum_{i=1}^{2} Q_{X i}\left(1-e^{-C_{X i} \bar{\varepsilon}^{p}}\right)
$$

where $r_{\phi}=\Sigma_{\phi}^{y} / \bar{\sigma}$ is constant and $\alpha_{\phi}(0)=0$ has been used. The yield stress, $\sigma_{\phi}^{y}$, can now be expressed as a function of the equivalent plastic strain, $\bar{\varepsilon}^{p}$.

$$
\sigma_{\phi}^{y}\left(\bar{\varepsilon}^{p}\right)=r_{\phi} \begin{cases}\sigma_{0}+\sum_{i=1}^{2}\left[Q_{R i}\left(1-e^{-C_{R i} \bar{\varepsilon}^{p}}\right)+Q_{X i}\left(1-e^{-C_{X i} \bar{\varepsilon}^{p}}\right)\right] & \bar{\varepsilon}^{p} \leq \varepsilon^{t} \\ A+B\left(\bar{\varepsilon}^{p}\right)^{C}+\sum_{i=1}^{2} Q_{X i}\left(1-e^{-C_{X i} \bar{\varepsilon}^{p}}\right) & \bar{\varepsilon}^{p}>\varepsilon^{t}\end{cases}
$$

As can be seen from Equation (27), mixed hardening may, in the special case of monotonic loading, be interpreted as the sum of isotropic and kinematic hardening, see Figure 15. The total stress at $100 \%$ plastic strain, $\sigma_{100}$, can now be expressed as the sum of the isotropic stress at $100 \%$ plastic strain, $\sigma_{100}^{\prime}$, and the saturation of the kinematic hardening.

$$
\sigma_{100}=\sigma_{100}^{\prime}+\sum_{i=1}^{2} Q_{X i}
$$

In order to simplify the parameter identification procedure, a linear mixture between the isotropic and kinematic hardening has been assumed

$$
\begin{aligned}
& Q_{R i}=\left(1-\beta_{i}\right) Q_{i}, \quad Q_{X i}=\beta_{i} Q_{i}, \quad i=1,2 \\
& C_{R i}=C_{X i}=C_{i}, \quad i=1,2
\end{aligned}
$$

where $\beta_{i}$ determines the amount of kinematic hardening. The monotonic hardening behaviour for strains $\bar{\varepsilon}^{p} \leq \varepsilon^{t}$ given in Equation (27) is independent of $\beta_{i}$. 
However, for strains $\bar{\varepsilon}^{p}>\varepsilon^{t}, \beta_{i}$ influences the hardening, which requires that $\beta_{i}$ must be identified prior, or simultaneously, to the $\sigma_{100}^{\prime}$ parameter. Furthermore, a restriction $\beta_{i} \leq 0.9$ was made in order to avoid unfeasible values of $C$.

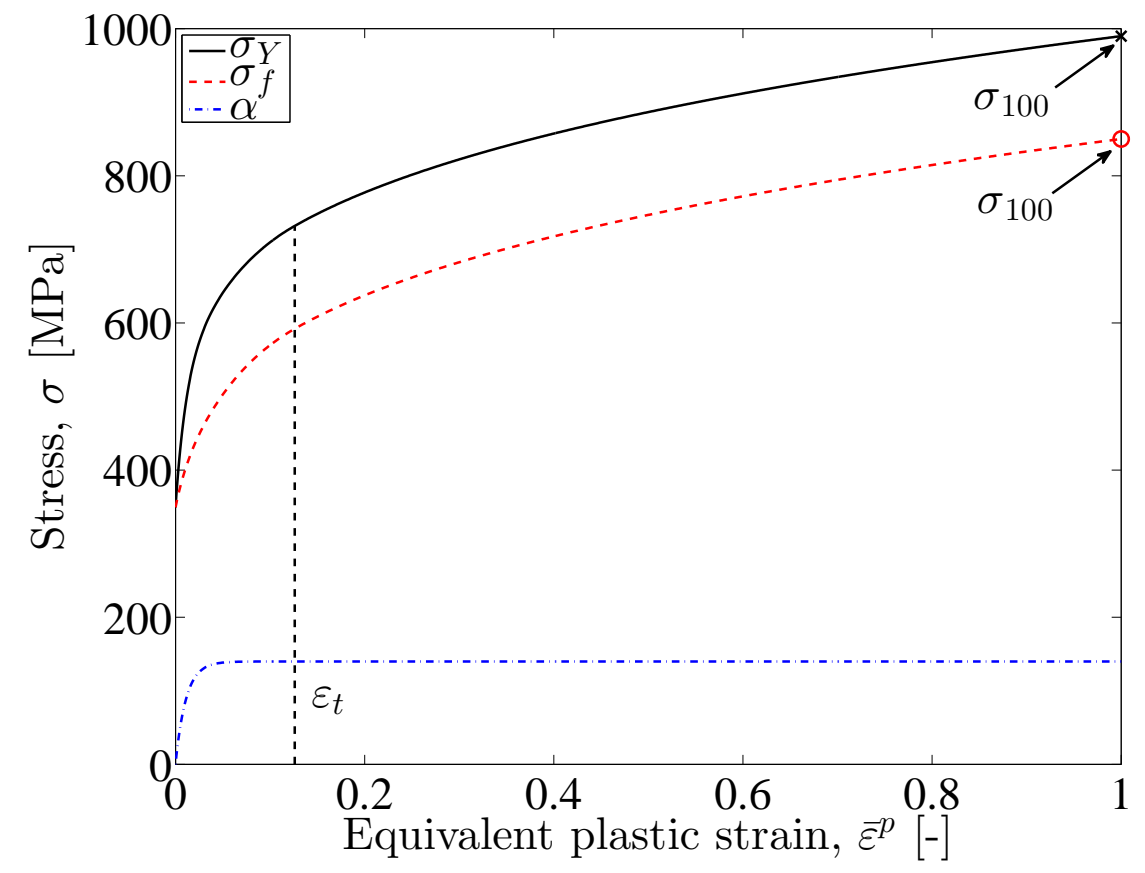

Figure 15: Hardening decomposition in the case of monotonic loading.

\subsection{Strain rate sensitivity}

Many metals show positive strain rate sensitivity, SRS, i.e. they show an increased stress response when subjected to an increased strain rate. Two commonly used assumptions to account for the SRS are an additive or a multiplicative decomposition of the flow stress. In this work the SRS has been assumed to follow a multiplicative decomposition and the flow stress becomes

$$
\sigma_{f}\left(\bar{\varepsilon}^{p}, \dot{\bar{\varepsilon}}^{p}\right)=\sigma_{y}\left(\bar{\varepsilon}^{p}\right) H\left(\dot{\bar{\varepsilon}}^{p}\right)
$$

where the SRS function $H$ scales the plastic hardening. Several different SRS functions have been proposed in the literature, e.g.

$$
H\left(\dot{\bar{\varepsilon}}^{p}\right)= \begin{cases}1+\left(\frac{\dot{\dot{\varepsilon}}^{p}}{\dot{\varepsilon}_{0}}\right)^{q} & \text { Cowper and Symonds (1957) } \\ 1+q \ln \left(\frac{\dot{\bar{\varepsilon}}^{p}}{\dot{\varepsilon}_{0}}\right) & \text { Johnson and Cook (1983) } \\ \left(1+\frac{\dot{\bar{\varepsilon}}^{p}}{\dot{\varepsilon}_{0}}\right)^{q} & \text { Tarigopula et al. (2006) }\end{cases}
$$


Diffuse necking under uniaxial tension is relatively unaffected by adding SRS. However, the SRS gives a stabilising effect in localised necking, cf. Marciniak et al. (2002). The SRS function according to Tarigopula et al. (2006) has been used in Paper III, Paper VI and Paper V with parameter settings according to Larsson (2012).

\subsection{Elastic stiffness degradation}

The amount of springback that occurs after unloading in a sheet metal forming operation is roughly proportional to the ratio between the yield stress and the Young's modulus. The phenomenon is particular pronounced in high-strength steels and aluminium due to these materials' high yield strength relative to the Young's modulus. Numerical experiments have shown that elastic stiffness decreases with prestraining, see e.g. Yamaguchi et al. (1998). In order to accurately capture the springback in numerical simulations, the phenomenon of elastic stiffness degradation needs to be accounted for. In Paper VI the elastic stiffness has been given as a function of the effective plastic strain, see e.g. Yoshida et al. (2002)

$$
E_{a v}\left(\bar{\varepsilon}^{p}\right)=E_{0}-\left(E_{0}-E_{s a t}\right)\left(1-e^{\xi \bar{\varepsilon}^{p}}\right)
$$

where $E_{a v}$ is the degraded average elastic stiffness during unloading, $E_{0}$ the initial Young's modulus, $E_{\text {sat }}$ the saturation value of the degradation, and $\xi$ is the rate of degradation. The parameters for the elastic degradation have been obtained from cyclic tensile tests by Aspenberg et al. (2012). A schematic view of the identification procedure is shown in Figure 16.

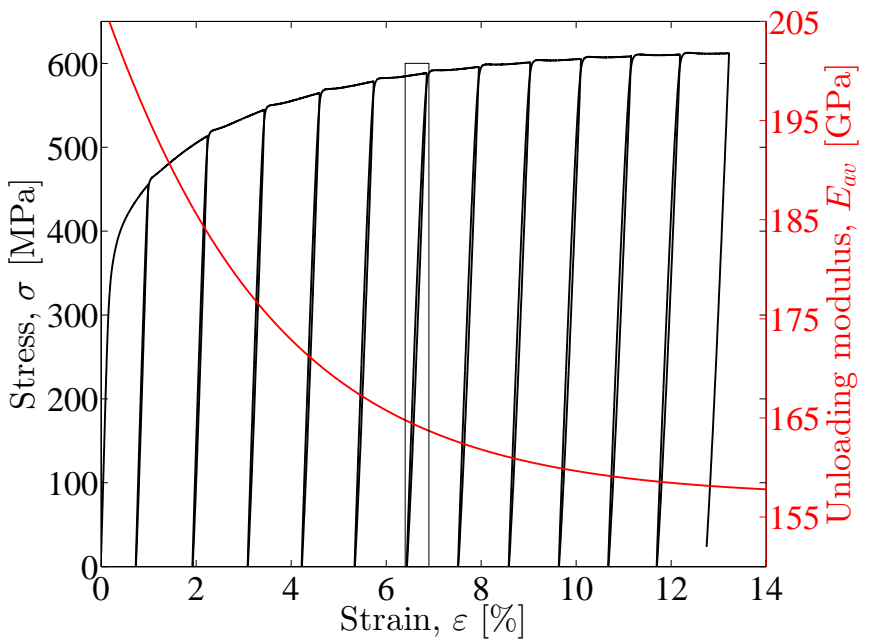

(a)

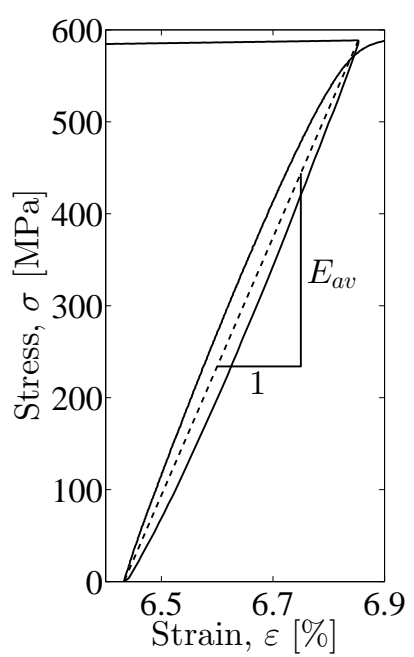

(b)

Figure 16: Elastic stiffness degradation. (a) cyclic stress response and (b) measure of unloading modulus $E_{a v}$. 



\section{Modelling instability}

Instabilities arise when strain hardening can no longer compensate for area reduction. Two typical instabilities in sheet metals are diffuse and localised necking, see Chapter 2. Since considerable deformation still is possible after diffuse necking, this state is usually not considered as a limiting case in sheet metal applications, cf. da Rocha et al. (1985). Prediction of instability in sheet metals has been paid considerable attention in the literature and analytical models both for diffuse necking, cf. Swift (1952), and localised necking, cf. Hill (1952), have been proposed. In Aretz (2004) a strategy is provided for the computational implementation of the models according to Hill (1952), Swift (1952) and Hora et al. (1996).

At localised instability, deformation takes place in a narrow band of the same width as the thickness of the sheet, see e.g. Dieter (1986). Due to the localisation, further deformation will rapidly lead to a material fracture. The prediction of the onset of localised instability is therefore crucial in order to identify the correct failure behaviour. The Marciniak and Kuczyński (1967) and the FE patch are two methods often used to identify instabilities in a general sheet metal application. These methods are described in the following.

\subsection{The Marciniak and Kuczyński model}

The model described by Marciniak and Kuczyński (1967), often referred to as the M-K model, considers an imperfection or defect in the sheet, most often realised as a thickness reduction over a narrow band, see Figure 17.
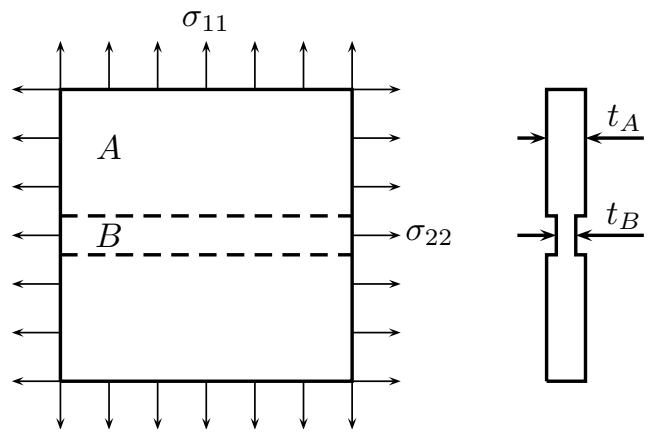

Figure 17: The geometry for the $M-K$ model. 
Elastic deformations are neglected and all subsequent strains are plastic. The stress in the 11-direction follows from equilibrium across the imperfection

$$
\sigma_{11}^{B}=\frac{t_{A}}{t_{B}} \sigma_{11}^{A}
$$

where the index $A$ and $B$ denote entities outside and within the imperfection, respectively. Compatibility in the 22-direction requires

$$
\varepsilon_{22}^{A}=\varepsilon_{22}^{B} \Leftrightarrow \mathrm{d} \varepsilon_{22}^{A}=\mathrm{d} \varepsilon_{22}^{B}
$$

A plane stress state is assumed and the material is considered as plastically incompressible. Furthermore, proportional loading path and deformation of the region $A$ is assumed, i.e.

$$
\boldsymbol{\sigma}^{A}=\sigma_{11}^{A}\left[\begin{array}{ccc}
1 & 0 & 0 \\
0 & \gamma_{A} & 0 \\
0 & 0 & 0
\end{array}\right], \quad \varepsilon^{A}=\varepsilon_{11}^{A}\left[\begin{array}{ccc}
1 & 0 & 0 \\
0 & \beta_{A} & 0 \\
0 & 0 & -\left(1+\beta_{A}\right)
\end{array}\right]
$$

where $\gamma_{A}$ and $\beta_{A}$ describe the loading and deformation ratios, respectively. Since the material is assumed to follow an associated flow rule the strain ratio, $\beta_{A}$, can be expressed as

$$
\beta_{A}=\left.\frac{\partial \bar{\sigma} / \partial \sigma_{22}}{\partial \bar{\sigma} / \partial \sigma_{11}}\right|_{\sigma_{11}=1, \sigma_{22}=\gamma_{A}, \sigma_{12}=0}
$$

During loading the yield condition is first met in region $B$, since the stress in the length direction is slightly larger here, i.e. the stress state in region $A$ is at $A_{0}$ and the stress state in region $B$ is at $B_{0}$ in Figure 18(a). However, due to the compatibility condition, Equation (34), the stress state in region $A$ must also reach the yield condition in order to permit plastic deformation. Simultaneously, equilibrium must be maintained. In order to accomplish this, the stress in region $B$ must move along the yield surface, i.e. the stress state in region $B$ moves from point $B_{0}$ towards point $B_{1}$ in Figure 18(a). When the yield limit is reached in region $A$, i.e. point $A_{1}$ in Figure 18(a), plastic deformation can occur in both regions while Equation (34) remains fulfilled. The directions of plastic flow in the two regions will differ since the stress states differ. Continuous deformation will move the stress state in region $B$ towards a plane strain situation. When the plane strain condition is reached, i.e. point $B_{f}$ in Figure 18(a), instability is assumed to occur. Since the original M-K model assumes that the imperfection is perpendicular to the major principal stress, it is only valid on the positive side of the FLD. By allowing the imperfection to appear at an arbitrary angle to the major principal stress, a model valid over the entire domain of the FLD can be obtained, cf. Stören and Rice (1975). 


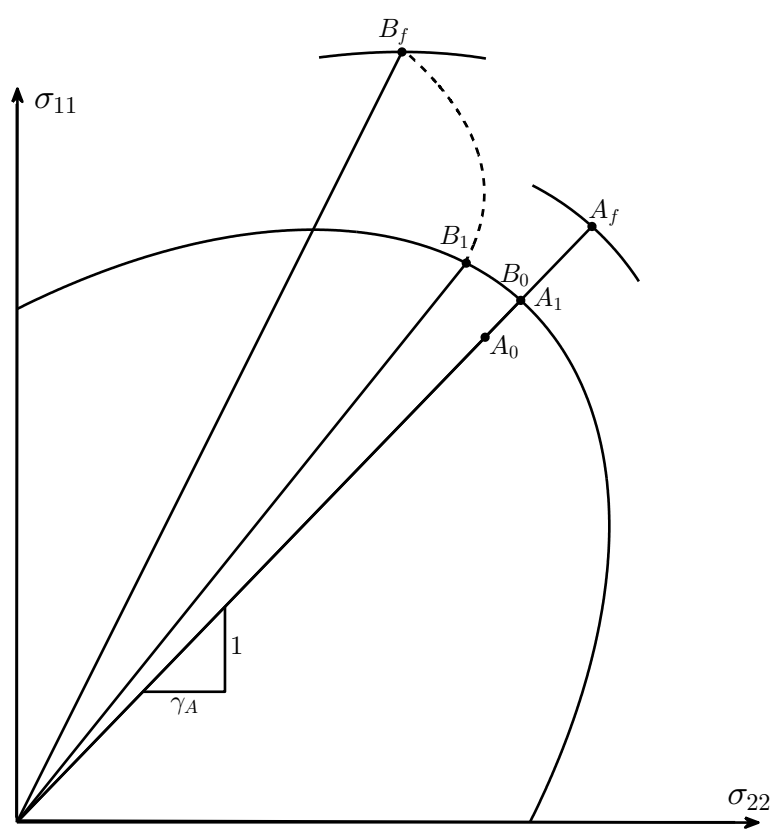

(a)

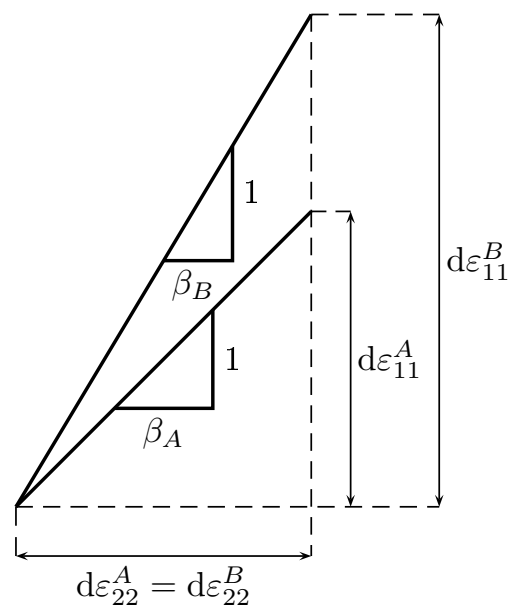

(b)

Figure 18: $M-K$ model (a) stress state for region $A$ and $B$ and (b) relationship between the strain paths.

\subsection{Finite element model}

A detailed patch of finite elements can be used in order to identify the onset of localised instabilities at linear strain paths as an FLC in the FLD, cf. Lademo et al. (2004a) and Lademo et al. (2004b). Also for a more general loading situation, the FE models together with the constitutive laws can be used to capture instabilities. The thickness imperfection in the M-K model may, in the FE model, be realised as an initial inhomogeneity in the thickness distribution. Lademo et al. (2004a) describe the thickness variation as a normally distributed random field with mean value $\mu$ and standard deviation, usually denoted $\sigma$. However, according to Fyllingen et al. (2009) one drawback of this method is that the variation depends on the number of nodes. Hence, a refinement of the FE mesh will lead to a different random field. Consequently the variation in thickness was, in this work, described independently of the FE mesh

$$
t(x, y)=\mu(x, y)+Z(x, y)
$$

where both the mean value, $\mu$, and the residual term, $Z$, may depend on the global coordinates $x$ and $y$. In this work the mean value was given as a constant, i.e. $\mu(x, y)=\mu$, and for the residual term, $Z$, a Gaussian zero mean homogeneous random field according to Shinozuka and Deodatis (1996) was used.

By introducing a thickness inhomogeneity in the FE model the localised instability was accurately captured both for shell and solid elements, cf. Paper II and Paper III. 


\subsection{Evaluation of instability in finite element models}

Since the thickness instability develops gradually, especially when a $C^{0}$ continuous element formulation is used, it is necessary to find a consistent method of defining the onset of instability. In Lademo et al. (2004a) and Lademo et al. (2004b) the limit strains causing localisation are considered as the global strains on the patch when an instability has occurred in any element. However, in Paper II the local strains in an element within the localisation area are considered. In order to find the strain limit at localised necking in the patch, two elements are considered: one inside the localisation zone and one some distance remote to it, see Figure 19(a) elements $A$ and $B$, respectively. The onset of instability has then been defined as the event of subsequently increasing strains in the finite element within the localisation zone at a stage when the strains in the remote element do not increase, see Figure 19(b). By using this method on the square patch subjected to linear strain paths, an FLC for the localised instability can be defined.

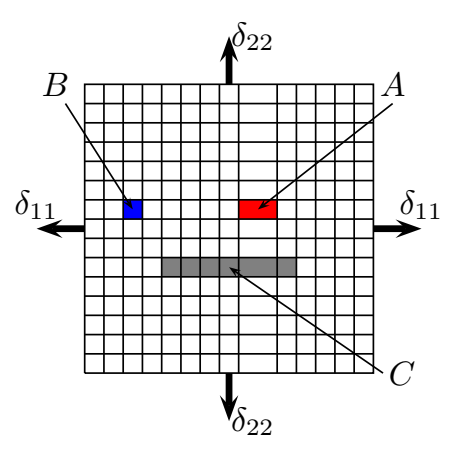

(a)

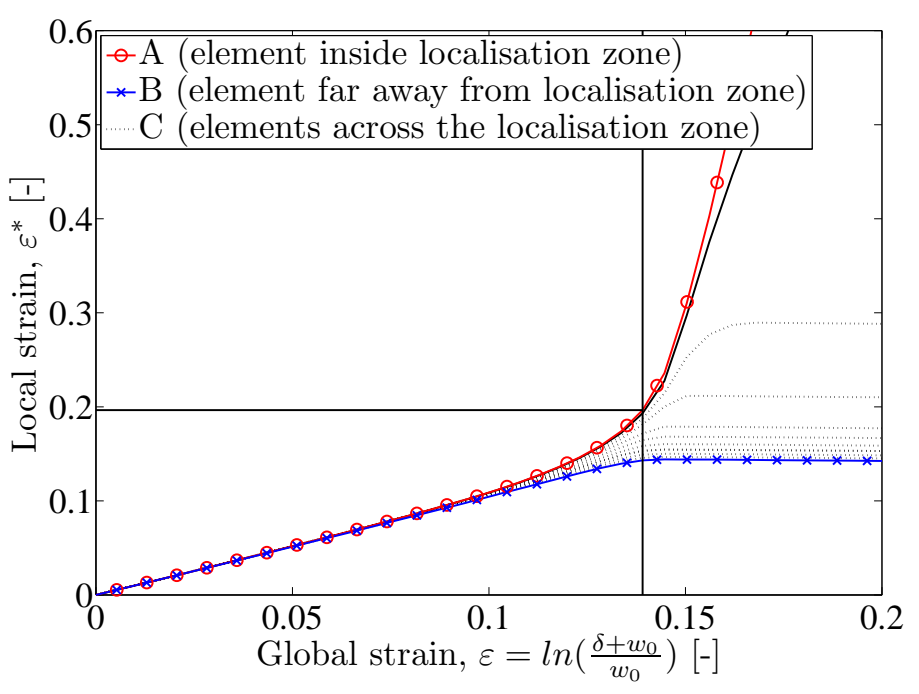

(b)

Figure 19: Evaluation procedure for instability limits, (a) chosen elements and (b) local vs. global strain.

In contrast to Paper II, where the aim was to identify the instability limit, the aim of Paper III was to examine if instability had occurred before fracture. In order to predict if instability has occurred, a similar evaluation method as was used in the experimental evaluation described in Section 7.6 was also used on the simulation results. At the moment corresponding to fracture, lines of elements across the specimen were selected and the principal strains evaluated and plotted against their position along these lines. The strain points that show a significantly larger major strain compared to their neighbours were excluded and a polynomial was fitted to the remaining strains. The strain causing instability has then been defined as the maximum strain of this polynomial fit. 


\section{Fracture modelling}

From a micromechanical point of view, ductile fracture is characterised by nucleation, growth and coalescence of voids in the material until the load-bearing area has eventually been reduced and material separation occurs. The reduction in loadcarrying area leads to material softening. In damage models, material softening is coupled to the constitutive relation either by porous plasticity, cf. Gurson (1977), or by continuum damage mechanics, cf. Lemaitre (1985). In porous plasticity both plasticity and ductile fracture are described simultaneously. Porous plasticity is classified as a coupled ductile fracture criterion since it considers the effect of damage on the plastic flow. In continuum damage mechanics an additional damage evolution equation to represent the local distribution of voids is introduced. One way to consider damage evolution is based on a relationship between the initial and the damaged area in a certain direction, see Lemaitre and Chaboche (1990) and Figure 20.

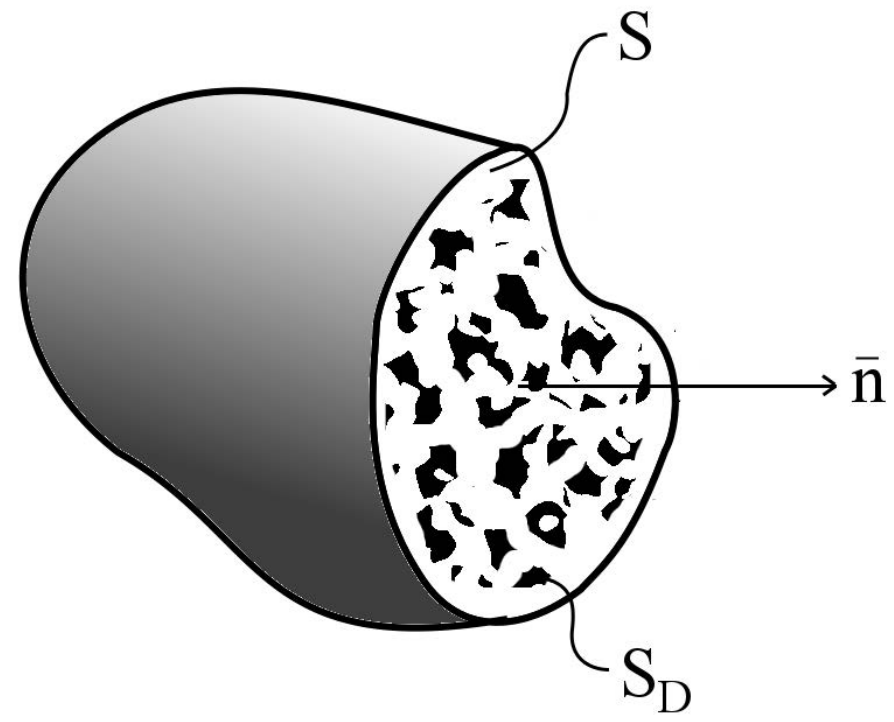

Figure 20: Initial area, $S$, and damage area, $S_{D}$, in the surface normal direction, $\bar{n}$.

The damage variable, $D_{n}$, can then be interpreted as the ratio between the damaged area, $S_{D}$, and the initial area, $S$, respectively.

$$
D_{n}=\frac{S_{D}}{S}
$$


In this definition of damage, ultimate fracture is expected when $D_{n}$ reaches unity, i.e. when the entire surface is damaged and there is no material left to maintain material connectivity. The area that can carry the load in the material is given by the difference between the initial and damaged areas $\left(S-S_{D}\right)$. The effective stress working on the material in the damaged region can be evaluated using the stress remote to the damaged region, $\sigma_{\infty}$, and the initial and damage areas

$$
\bar{\sigma}=\frac{S \sigma_{\infty}}{S-S_{D}}=\frac{\sigma_{\infty}}{1-D_{n}}
$$

Since a coupling between the damage model and the constitutive law is present both in porous plasticity and in continuum damage mechanics, these models are difficult to calibrate which limits their industrial applicability. In un-coupled fracture models, on the other hand, the constitutive law is not affected before fracture. Most un-coupled fracture models consider fracture to occur when a critical state value is reached.

Several different phenomena may contribute to the failure process. In Teirlinck et al. (1988) four failure phenomena observed in uniaxial tension specimens are described: (i) plastic failure, (ii) ductile fracture, (ii) shear fracture and (iv) cleavage and brittle intergranular failure. Failure type (iv), cleavage and brittle intergranular failure, is considered as a brittle fracture, which is not included in this study. The three first failure types are also identified in sheet metals, see e.g. Hooputra et al. (2004), where the term plastic failure is generalised to represent any sheet instability. Plastic failure or sheet instability is often the primary mechanism leading to failure, even if no material separation occurs at the point of instability. Failure due to sheet instability is examined separately in Chapter 5. In this chapter, criteria for ductile tensile and ductile shear fractures are presented.

\subsection{Phenomenological fracture criteria}

Even if the un-coupled phenomenological fracture criteria do not affect the constitutive laws and thus produce a material softening, it is useful to consider them as a limit state of a damage evolution process. A general form of a ductile fracture criterion can be expressed

$$
D=\int_{0}^{\varepsilon_{f}} F(\text { state variables }) \mathrm{d} \bar{\varepsilon}^{p} \leq C
$$

where the function, $F$, may depend on any state variable. The state variables can be divided into observable variables, e.g. temperature, $T$, total strain tensor, $\varepsilon$, or internal, e.g. plastic strain tensor, $\boldsymbol{\varepsilon}^{p}$, or stress tensor, $\boldsymbol{\sigma}$, among others. Numerous fracture models have been presented in the literature. For an overview, see e.g. Wierzbicki et al. (2005). The simplest form of Equation (40) is when $F \equiv 1$, in 
which case the model predicts the equivalent plastic strain to fracture. However, a fracture criterion given by a constant equivalent plastic strain to fracture contradicts experimental observations, cf. Paper III. The five fracture criteria used in this work are presented in the sections below.

\section{The Cockroft-Latham criterion}

Cockroft and Latham (1968) suggested a criterion based on accumulated stress and plastic strain. More precisely they argued that the plastic work must be an important factor for the fracture. The amount of plastic work done per unit volume at fracture is

$$
W^{p}=\int_{0}^{\varepsilon_{f}} \bar{\sigma} \mathrm{d} \bar{\varepsilon}^{p}
$$

where $\bar{\sigma}$ is the effective stress, $\varepsilon_{f}$ is the fracture strain, and $\mathrm{d} \bar{\varepsilon}^{p}$ is the incremental equivalent plastic strain. However, the effective stress $\bar{\sigma}$, unlike the major principal stress $\sigma_{1}$, is not influenced by the shape of the necked region. A criterion based on the total amount of plastic work will therefore predict a fracture independent of this shape, which contradicts experimental results. Therefore, the total amount of plastic work cannot provide a good criterion by itself. A more reasonable fracture criterion would be to take the magnitude of the largest tensile principal stress into account. Cockroft-Latham therefore proposed that fracture occurs in a ductile material when

$$
W=\int_{0}^{\varepsilon_{f}}\left(\frac{\left\langle\sigma_{1}\right\rangle}{\bar{\sigma}}\right) \bar{\sigma} \mathrm{d} \bar{\varepsilon}^{p}
$$

reaches a critical value, $W_{c}$, for a given temperature and strain rate. The nondimensional stress concentration factor, $\left(\frac{\left\langle\sigma_{1}\right\rangle}{\bar{\sigma}}\right)$, represents the effect of the largest tensile stress, $\left\langle\sigma_{1}\right\rangle=\max \left(\sigma_{1}, 0\right)$. The reduced form

$$
W=\int_{0}^{\varepsilon_{f}}\left\langle\sigma_{1}\right\rangle \mathrm{d} \bar{\varepsilon}^{p} \leq W_{c}
$$

is used in the fracture evaluation, and fracture is expected when $W$ reaches a critical value, $W_{c}$, which is determined from experiments. The Cockroft-Latham criterion implies that fracture in a ductile material depends both on the stress and plastic strain states, i.e. neither stress nor strain alone can describe ductile fracture. The benefit of using the largest principal stress, $\sigma_{1}$, is observed when it is be expressed as a function of the hydrostatic pressure, $p$, the second invariant of the deviator stress, $J_{2}$ and the Lode angle, $\theta$

$$
\sigma_{1}=-p+\sqrt{\frac{4 J_{2}}{3}} \cos \theta
$$


Thus, the choice of $\sigma_{1}$ means that the fracture depends on the stress triaxiality, see Equation (8). The Cockroft-Latham criterion predicted ductile tensile fracture with a good level of accuracy in the study presented in Paper II. However, the ductile shear fracture was not accurately captured. Han and Kim (2003) presented a criterion, which combines the model by Cockcroft-Latham with a maximum shear stress criterion and the through-thickness strain in order to improve the prediction of both ductile tensile and ductile shear fractures.

\section{The extended Cockroft-Latham criterion}

Another extension to the Cockcroft-Latham criterion was presented by Gruben et al. (2012). Similar to the Cockcroft-Latham criterion, the extended criterion is assumed to be driven by the plastic work. However, in the extended CockcroftLatham criterion a dependency of the maximum shear stress has been added in order to amplify the influence of the Lode angle. The extended Cockcroft-Latham criterion is formulated

$$
W=\int_{0}^{\varepsilon_{f}}\left\langle\frac{\phi \sigma_{1}+(1-\phi)\left(\sigma_{1}-\sigma_{3}\right)}{\bar{\sigma}}\right\rangle^{\gamma} \bar{\sigma} \mathrm{d} \bar{\varepsilon}^{p} \leq W_{c}
$$

where the principal stresses are ordered so that $\sigma_{1} \geq \sigma_{2} \geq \sigma_{3}$, and $W_{c}>0,0 \leq$ $\phi \leq 1$ and $\gamma>0$ are material parameters. By setting $\phi=1$ and $\gamma=1$ the original Cockcroft-Latham criterion is obtained. In Gruben et al. (2013) the extended Cockcroft-Latham criterion showed promising results for both crack initiation and crack propagation in a diversity of test specimens.

\section{The Johnson-Cook criterion}

The Johnson and Cook (1985) criterion was originally developed for dynamic loading conditions, such as high velocity impact. In these conditions a wide range of strains, strain rates and temperatures may occur. The Johnson-Cook fracture criterion is a purely phenomenological model which is based on a similar relationship as the hardening model presented by Johnson and Cook (1983). The model uses a damage parameter $D$, and when this parameter reaches the value unity, ultimate fracture is assumed. The definition of the damage parameter is

$$
D=\int_{0}^{\varepsilon_{f}} \frac{1}{\Phi\left(\eta, \dot{\bar{\varepsilon}}^{p}, T\right)} \mathrm{d} \bar{\varepsilon}^{p} \leq 1
$$

where $\varepsilon_{f}$ is the equivalent strain at fracture and

$$
\Phi\left(\eta, \dot{\bar{\varepsilon}}^{p}, T\right)=\left(c_{1}+c_{2} e^{-c_{3} \eta}\right)\left[1+c_{4} \ln \left(\frac{\dot{\bar{\varepsilon}}^{p}}{\dot{\varepsilon}_{0}}\right)\right]\left(1+c_{5} T\right)
$$


$c_{1}, \ldots, c_{5}$ are material constants, which can be determined from experiments, $\eta$ is the stress triaxiality, $\dot{\vec{\varepsilon}}^{p}$ is the equivalent plastic strain-rate, $\dot{\varepsilon}_{0}$ is a reference strain-rate and $T$ is the temperature. In Paper IV the effects of strain rate and temperature were neglected and a reduced form of the Johnson-Cook fracture criterion was used, i.e. $c_{4}=0$ and $c_{5}=0$. The reduced Johnson-Cook criterion gives a monotonically decreasing fracture strain with increasing stress triaxiality $\eta$ if $c_{3}>0$.

\section{The modified Mohr-Coulomb criterion}

The Mohr-Coulomb criterion states that fracture occurs at the combination of normal and shear stress

$$
\tau+c_{1} \sigma_{n}=c_{2}
$$

where $c_{1}$ and $c_{2}$ are material parameters, and $\tau$ and $\sigma_{n}$ are the shear and normal stresses on a critical plane in the material. The parameters $c_{1}$ and $c_{2}$ are often referred to as the friction and cohesion parameters, respectively. The Mohr-Coulomb criterion has mainly been used for brittle materials. A modification of the MohrCoulomb criterion for ductile fracture was presented by Bai and Wierzbicki (2010), in which the criterion is expressed in terms of the principal stresses

$$
\left(\sqrt{1+c_{1}^{2}}+c_{1}\right) \sigma_{1}-\left(\sqrt{1+c_{1}^{2}}-c_{1}\right) \sigma_{3}=2 c_{2}
$$

where $\sigma_{1}$ and $\sigma_{3}$ are the major and minor principal stresses, respectively. Using the Haigh-Westergaard stress representation and the stress triaxiality, Equation (49) can be reformulated as

$$
\bar{\sigma}_{v M}=\frac{c_{2}}{\sqrt{\frac{1+c_{1}^{2}}{3}} \cos \left(\theta-\frac{\pi}{6}\right)+c_{1}\left[\eta-\frac{1}{3} \sin \left(\theta-\frac{\pi}{6}\right)\right]}
$$

where $\theta$ is the Lode angle and $\eta$ is the stress triaxiality. If $J_{2}$-flow theory is used a direct correlation between the von Mises stress and the flow stress is obtained, i.e. $\bar{\sigma}_{v M}=\sigma_{f}\left(\bar{\varepsilon}^{p}, \dot{\bar{\varepsilon}}^{p}\right)$. For a constant strain rate the equivalent plastic strain that fulfils Equation (50) can be found as $\bar{\varepsilon}_{f}^{p}$. The modified Mohr-Coulomb criterion may then be expressed as

$$
D=\int_{0}^{\varepsilon_{f}} \frac{1}{\bar{\varepsilon}_{f}^{p}} d \bar{\varepsilon}^{p} \leq 1
$$

When the $J_{2}$-flow theory not is used, a relationship between the von Mises and the effective stress used must be identified. In Paper IV, the Mohr-Coulomb criterion was used in combination with the Yld2003 effective stress. 


\section{The Bressan-Williams criterion}

Shell elements are mainly used in modelling sheet metal geometries, but are frequently restricted to plane stress conditions. Thus, they are not able to describe transversal shear stresses. It is therefore sometimes necessary to consider a fracture criterion that can be used to predict this phenomenon. Bressan and Williams (1983) suggested a model to predict instability through the thickness of a sheet metal. They suggested that an incremental plastic strain exists at failure in an inclined direction through the thickness of the sheet, i.e. $\mathrm{d} \varepsilon_{t}^{p}=0$ in the $\boldsymbol{e}_{t}$-direction as shown in Figure 21. By assuming that the directions of principal stress and strains coincide, the stress and strain state can be found as

$$
\boldsymbol{\sigma}=\left[\begin{array}{ccc}
\sigma_{1} & 0 & 0 \\
0 & \sigma_{2} & 0 \\
0 & 0 & 0
\end{array}\right], \quad \mathrm{d} \boldsymbol{\varepsilon}^{p}=\left[\begin{array}{ccc}
\mathrm{d} \varepsilon_{1}^{p} & 0 & 0 \\
0 & \mathrm{~d} \varepsilon_{2}^{p} & 0 \\
0 & 0 & \mathrm{~d} \varepsilon_{3}^{p}
\end{array}\right]
$$

The strain increment in the $\boldsymbol{e}_{t}$-direction and the shear stress on the inclined surface are

$$
\mathrm{d} \varepsilon_{t}^{p}=\sin ^{2} \theta \mathrm{d} \varepsilon_{1}^{p}+\cos ^{2} \theta \mathrm{d} \varepsilon_{3}^{p}=0
$$

and

$$
\sigma_{t n}=-\left(\sigma_{1}\right) \sin \theta \cos \theta
$$

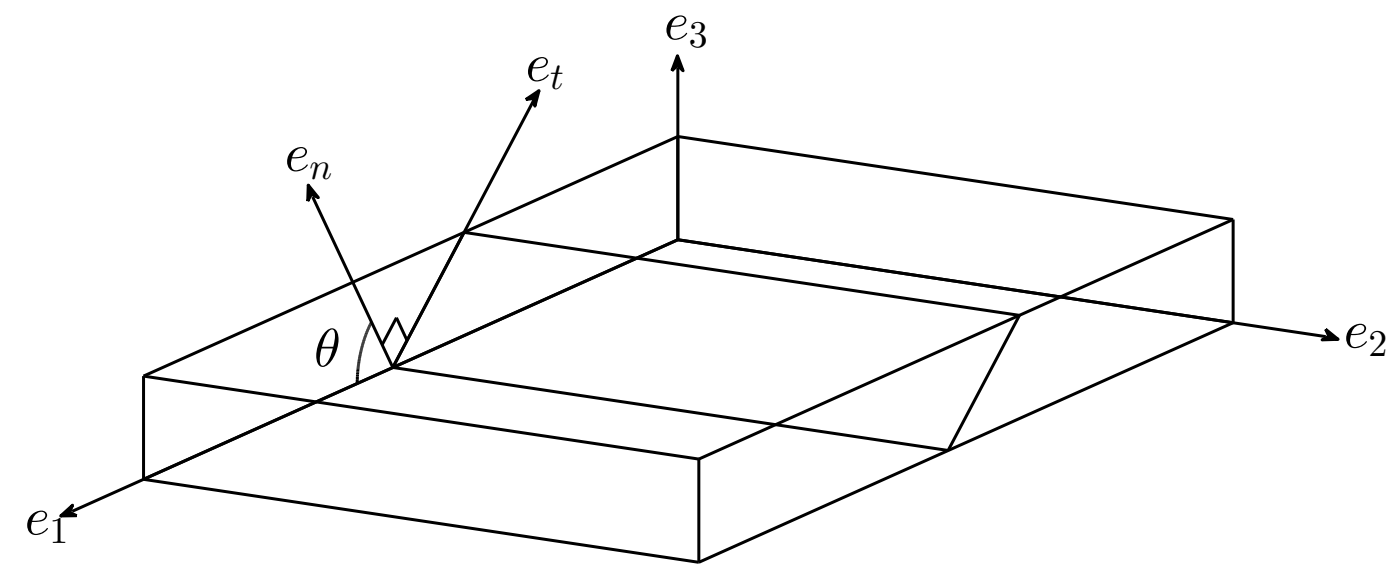

Figure 21: Inclined plane through the thickness of the sheet.

Assuming that fracture occurs when the shear stress, $\sigma_{t n}$, on the inclined surface reaches a critical value $\tau_{c}$, and that the material is plastically incompressible, the following relationship are obtained

$$
\cos 2 \theta=\frac{-\mathrm{d} \varepsilon_{2}^{p}}{2 \mathrm{~d} \varepsilon_{1}^{p}+\mathrm{d} \varepsilon_{2}^{p}}=\frac{-\beta}{2+\beta}
$$


and

$$
\sin 2 \theta=-\frac{2 \tau_{c}}{\sigma_{1}}
$$

Here $\beta=\mathrm{d} \varepsilon_{2}^{p} / \mathrm{d} \varepsilon_{1}^{p}$ is the ratio between the in-plane principal plastic strains and $\tau_{c}$ is a material constant. From Equations (55) and (56) the following inequality can be obtained

$$
\tau=\frac{\sigma_{1}}{2} \sqrt{1-\left(\frac{-\beta}{2+\beta}\right)^{2}} \leq \tau_{c}
$$

where $\sigma_{1} / 2$ is the shear stress on the inclined surface, cf. Figure 21. As long as the inequality is fulfilled no fracture is expected due to the through-thickness shear. However, in Paper II a normal stress through the thickness has been introduced to obtain $C^{0}$ continuity across the element edges. Therefore, the criterion in Equation (57) is modified such that

$$
\tau=\frac{\sigma_{1}-\sigma_{N D}}{2} \sqrt{1-\left(\frac{-\beta}{2+\beta}\right)^{2}} \leq \tau_{c}
$$

where $\sigma_{N D}$ is the through-thickness normal stress, and thus $\left(\sigma_{1}-\sigma_{N D}\right) / 2$ is the shear stress on the inclined surface.

\subsection{Anisotropic fracture criteria}

Material anisotropy in ductile fracture is only incorporated indirectly in most fracture criteria, i.e. following the anisotropic effective stress. In Paper V a material directional function, MDF, denoted $\Psi$, was introduced to consider the anisotropy in fracture. The MDF complemented the extended Cockroft-Latham criterion, but any of the previously presented fracture criteria may be used in a similar manner. A short summary of the five MDFs used in Paper $\mathbf{V}$ are given below.

\section{Material directional function, $\Psi^{(1)}$}

The first MDF is given as a ratio between the von Mises and the effective stresses actually used

$$
\Psi^{(1)}(\boldsymbol{\sigma})=\left(\frac{\bar{\sigma}_{v M}}{\bar{\sigma}}\right)^{c_{1}}
$$

where $c_{1}$ is a material parameter introduced in order to amplify the effect of anisotropy. 
Material directional function, $\Psi^{(2)}$

In the second MDF, the direction of the major principal stress relative to the RD was introduced. The MDF is expressed as

$$
\Psi^{(2)}(\boldsymbol{\sigma})=1+c_{1} \cos (2 \theta)+c_{2} \cos (4 \theta)
$$

where $\theta$ is the angle between the RD and the major principal stress, and $c_{1}$ and $c_{2}$ are material parameters.

\section{Material directional function, $\Psi^{(3)}$}

The third MDF was inspired by the work of Pietruszczak and Mroz (2000) in which microstructure tensors were used to predict the fracture anisotropy. The MDF is

$$
\Psi^{(3)}(\boldsymbol{\sigma})=c_{1} \frac{\operatorname{tr}\left(\boldsymbol{m}_{\mathbf{1}} \boldsymbol{\sigma}^{2}\right)}{\operatorname{tr} \boldsymbol{\sigma}^{2}}+c_{2} \frac{\operatorname{tr}\left(\boldsymbol{m}_{\mathbf{2}} \boldsymbol{\sigma}^{2}\right)}{\operatorname{tr} \boldsymbol{\sigma}^{2}}
$$

where $\boldsymbol{m}_{1}$ and $\boldsymbol{m}_{2}$ are the microstructure tensors defining planes normal and parallel to the RD

$$
\boldsymbol{m}_{1}=\left[\begin{array}{lll}
1 & 0 & 0 \\
0 & 0 & 0 \\
0 & 0 & 0
\end{array}\right] \quad \boldsymbol{m}_{2}=\left[\begin{array}{lll}
0 & 0 & 0 \\
0 & 1 & 0 \\
0 & 0 & 0
\end{array}\right]
$$

\section{Material directional function, $\Psi^{(4)}$}

The fourth MDF is an extension of the third, in which a microstructure tensor accounting for a skew plane was introduced. The chosen microstructure tensor is

$$
\boldsymbol{m}_{12}=\left[\begin{array}{lll}
0 & 1 & 0 \\
1 & 0 & 0 \\
0 & 0 & 0
\end{array}\right]
$$

However, since the symmetry properties of the fracture need to be satisfied, the $\boldsymbol{m}_{12}$ term is incorporated with an absolute value, i.e.

$$
\Psi^{(4)}(\boldsymbol{\sigma})=c_{1} \frac{\operatorname{tr}\left(\boldsymbol{m}_{\mathbf{1}} \boldsymbol{\sigma}^{2}\right)}{\operatorname{tr} \boldsymbol{\sigma}^{2}}+c_{2} \frac{\operatorname{tr}\left(\boldsymbol{m}_{\mathbf{2}} \boldsymbol{\sigma}^{2}\right)}{\operatorname{tr} \boldsymbol{\sigma}^{2}}+c_{3}\left|\frac{\operatorname{tr}\left(\boldsymbol{m}_{\mathbf{1 2}} \boldsymbol{\sigma}^{2}\right)}{\operatorname{tr} \boldsymbol{\sigma}^{2}}\right|
$$


Material directional function, $\Psi^{(5)}$

The fifth MDF is based on the work of Luo et al. (2012) and uses a scaling of the incremental equivalent plastic strain

$$
\Psi^{(5)}\left(\mathrm{d} \varepsilon^{p}\right)=\frac{\mathrm{d} \tilde{\varepsilon}^{p}}{\mathrm{~d} \bar{\varepsilon}^{p}}
$$

where $\mathrm{d} \bar{\varepsilon}^{p}$ is the incremental effective plastic strain and $\mathrm{d} \tilde{\varepsilon}^{p}$ is an incremental measure obtained from the incremental plastic strain tensor $\mathrm{d} \varepsilon_{i j}^{p}$. Thus

$$
\mathrm{d} \tilde{\varepsilon}^{p}=\sqrt{\frac{2}{3} \mathrm{~d} \varepsilon_{i j}^{p} A_{i j k l} \mathrm{~d} \varepsilon_{k l}^{p}}
$$

where $A_{i j k l}$ is a fourth order tensor representing the fracture anisotropy. By Voigt's notation this expression is

$$
\mathrm{d} \tilde{\varepsilon}^{p}=\sqrt{\frac{2}{3} \mathrm{~d} \varepsilon_{k}^{p} \beta_{i k} \beta_{l i} \mathrm{~d} \varepsilon_{l}^{p}}
$$

in which $\mathrm{d} \varepsilon_{k}^{p}$ denotes the increment in the plastic strain vector, where $\mathrm{d} \varepsilon_{k}^{p}=$ $\left[\mathrm{d} \varepsilon_{11}^{p}, \mathrm{~d} \varepsilon_{22}^{p}, \mathrm{~d} \varepsilon_{33}^{p}, \sqrt{2} \mathrm{~d} \varepsilon_{12}^{p}, \sqrt{2} \mathrm{~d} \varepsilon_{23}^{p}, \sqrt{2} \mathrm{~d} \varepsilon_{31}^{p}\right] . \boldsymbol{\beta}$ is the anisotropic fracture matrix defined as

$$
\boldsymbol{\beta}=\left[\begin{array}{cccccc}
c_{1} & 0 & 0 & 0 & 0 & 0 \\
0 & c_{2} & 0 & 0 & 0 & 0 \\
0 & 0 & c_{3} & 0 & 0 & 0 \\
0 & 0 & 0 & c_{4} & 0 & 0 \\
0 & 0 & 0 & 0 & 1 & 0 \\
0 & 0 & 0 & 0 & 0 & 1
\end{array}\right]
$$

By setting $c_{1}$ to $c_{4}$ to unity, d $\tilde{\varepsilon}^{p}$ is equal to the von Mises equivalent strain increment. More generally, the off-diagonal terms could be non-zero. 



\section{Mechanical experiments}

In this study seven different mechanical tests have been conducted in order to calibrate the investigated constitutive relations and fracture criteria:

- Pre-deformation tests

- Tensile tests

- In-plane shear tests

- Plane strain tensile tests

- Bulge tests

- Nakajima tests

- Exhaust bracket tests

The pre-deformation tests have been performed in an MTS hydraulic machine with a $250 \mathrm{kN}$ load cell. The tensile, in-plane shear, plane strain and stretching of the exhaust bracket tests have been carried out in an INSTRON 5582 machine with a $100 \mathrm{kN}$ load cell.

\subsection{Pre-deformation test}

Deformation of large specimens shown in Figure 22(a) was performed to create an initial state of nonlinear strain paths. The specimen length, width and thickness were $1100 \mathrm{~mm}, 125 \mathrm{~mm}$ and $1.5 \mathrm{~mm}$, respectively. The tests were performed under quasi-static loading conditions with a constant crosshead speed of $5 \mathrm{~mm} / \mathrm{min}$, which resulted in a strain-rate of approximately $10^{-4} \mathrm{~s}^{-1}$. The unloading was set to last for $1 \mathrm{~min}$. The design of the specimen was made in an attempt to maximise the zone of homogenous strain. The homogeneity of the strain field in the specimen was controlled both by ocular measurements and by FE simulations. The mid section of the specimen was divided into 16 equal sections, of which the thickness, width and length were measured both before and after completed loading.

The pre-deformations were performed with specimens from both the RD and the TD, i.e. $\psi=0^{\circ}$ and $\psi=90^{\circ}$ according to Figure 23. For each material direction, the specimens have been pre-deformed to two specific strain levels, one level in 
proximity to the strain close to diffuse necking and the other level chosen to be approximately half the first one. After the pre-straining operation tensile, shear and plane strain specimens were machined out from the centre part of the specimens, see Figure 22(b).

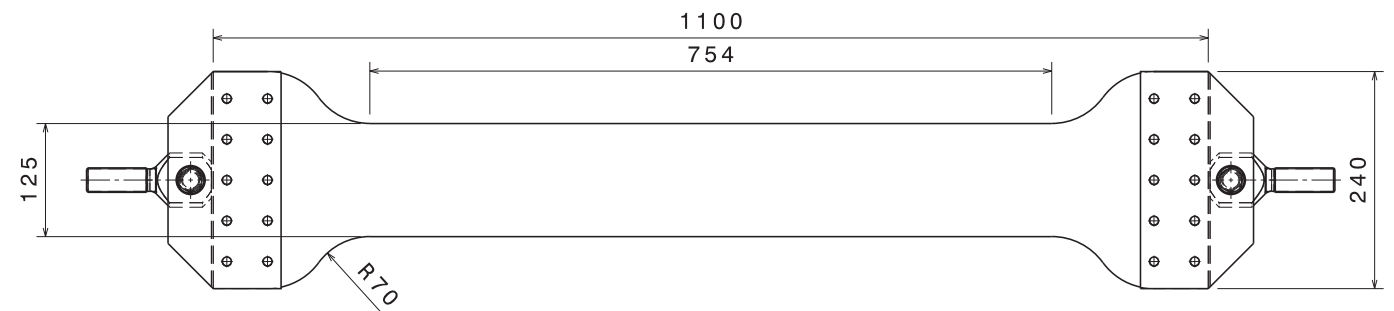

(a)

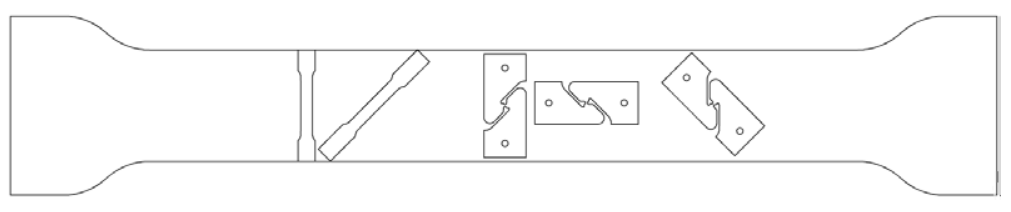

(b)

Figure 22: a) Undeformed geometry of specimen subjected to pre-straining. Dimensions in mm. b) Sketch including some cut-out specimens.

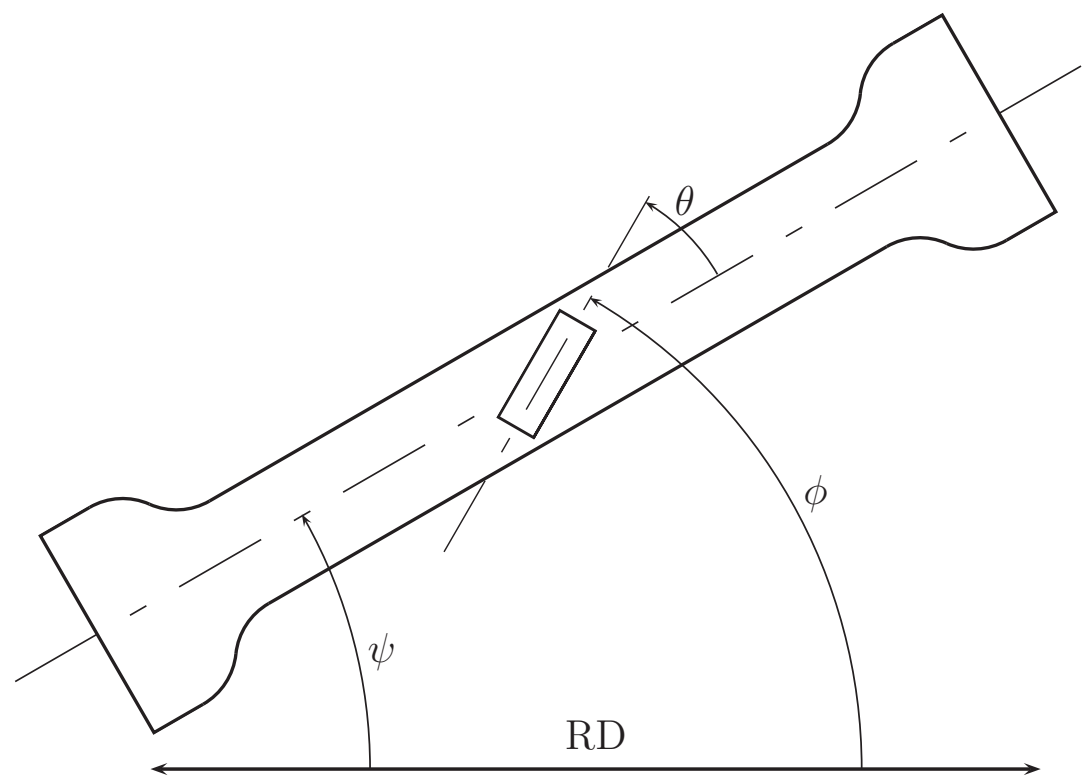

Figure 23: Angles defining pre-strain directions, $\psi$, and orientation of specimen used in subsequent tests, $\phi=\psi+\theta$. 


\subsection{Tensile test}

Tensile test specimens according to Figure 24(a) were performed in the $\phi=0^{\circ}, 45^{\circ}$ and $90^{\circ}$ directions, where $\phi$ is the angle to the RD, see Figure 23, both for the asreceived and for the pre-deformed material specimens. During the tensile tests the load, elongation and width were recorded. The elongation, $\varepsilon_{L}$, has been measured by an INSTRON 2620-601 extensometer with a gauge length of $L_{0}=12.5 \mathrm{~mm}$, and the width strain, $\varepsilon_{W}$, was measured with an MTS 632.19B-20 extensometer over the entire width of the specimen. The deformation was performed with a constant crosshead speed of $0.45 \mathrm{~mm} / \mathrm{min}$, which resulted in a strain-rate of approximately $10^{-4} \mathrm{~s}^{-1}$. The anisotropies in yield stress and plastic flow were evaluated directly from the tensile tests of the as-received specimens. Numerical simulation and inverse modelling were used to identify the kinematic hardening and to calibrate the fracture criteria.

\subsection{Plane strain tensile test}

The geometry of the plane strain tensile test (notched tensile test) is shown in Figure 24(b). Similar designs have been utilised in other studies, e.g. Lademo et al. (2008). The plane strain tests were performed in $\phi=0^{\circ}, 45^{\circ}$ and $90^{\circ}$ directions, with a displacement rate of $0.06 \mathrm{~mm} / \mathrm{min}$. During the test the load, grip motion, width reduction and midsection elongation were measured. The latter was measured by an INSTRON 2620-601 extensometer with a gauge length of $23 \mathrm{~mm}$, while the width reduction was measured by an MTS 632.19B-20 extensometer. The plane strain tests, in combination with inverse modelling, were used in order to calibrate the fracture criteria.

\subsection{In-plane shear test}

The geometry of the in-plane shear test specimen used in this study is shown in Figure 24(c). The shear tests are performed both on as-received and on predeformed specimens in the $\phi=0^{\circ}, 45^{\circ}$ and $90^{\circ}$ directions. The two attachments of the shear test specimen have been constructed in the form of a pin at each end to prevent rotational loading. In order to obtain a strain-rate of approximately $10^{-4} \mathrm{~s}^{-1}$, the displacement rate of $0.03 \mathrm{~mm} / \mathrm{min}$ was used. The shear tests results combined with inverse modelling were used to gain an accurate description of the hardening behaviour at large strains, to identify the yield surface exponent, and to calibrate the fracture criteria. 


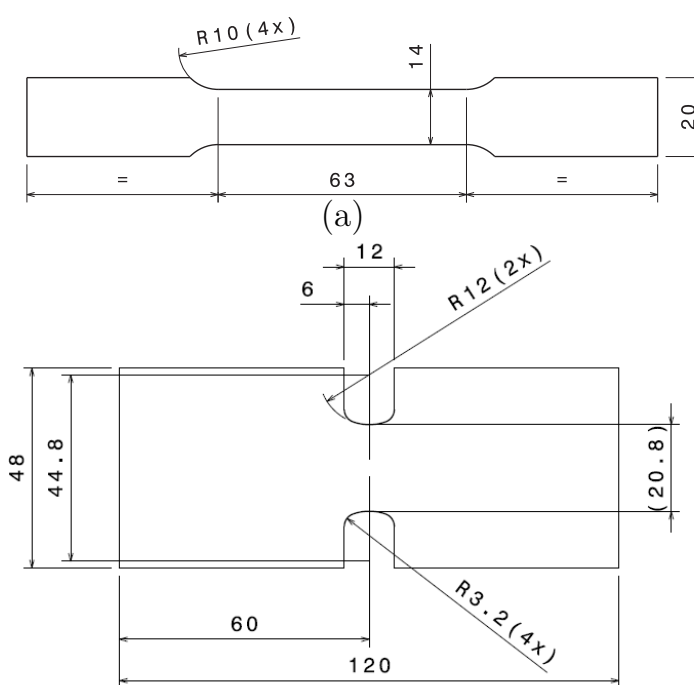

(b)

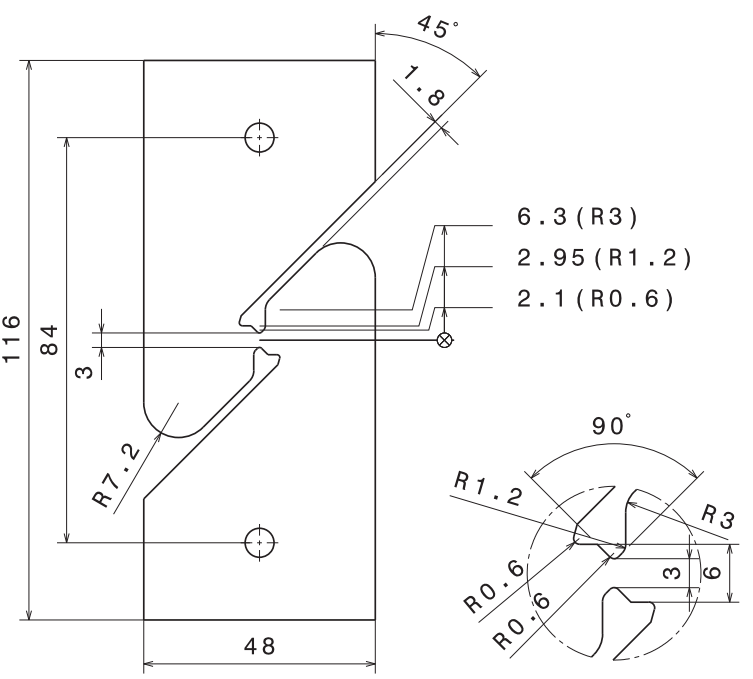

(c)

Figure 24: Geometry of (a) the tensile specimen, (b) the plane strain tension specimen and (c) the in-plane shear specimen. Dimensions in $\mathrm{mm}$.

\subsection{Balanced biaxial test}

A balanced biaxial bulge test was performed on the virgin materials. A pattern of randomly placed dots was sprayed on the sheet surface and the pressure was applied using a punch made of silicon. The specimen was video recorded by two cameras during the subsequent testing. The in-plane strains and the radius of the bulge were then evaluated from the recording of the pattern motion using an ARAMIS strain measurement system. Balanced biaxial tests were used in order to obtain the stress and strain ratios $r_{b}$ and $k_{b}$, respectively.

\subsection{Nakajima test}

A number of Nakajima tests, see ISO (2008), have been conducted in order to evaluate the failure behaviour. The tests were made on virgin material and the geometries, see Figure 25, were chosen so that the first quadrant $\left(\varepsilon_{1} \geq 0, \varepsilon_{2} \geq 0\right)$ of the FLD was covered.

The Nakajima tests were performed in an Interlaken ServoPress 150. The machine has a punch diameter of $100 \mathrm{~mm}$ and a $550 \mathrm{kN}$ load cell. The clamping force was limited to $700 \mathrm{kN}$ and the punch motion was set at $1 \mathrm{~mm} / \mathrm{s}$. During the test, the force and displacement of the punch were recorded. The specimens were treated with three layers of oil and plastic film to reduce friction. Before the test, a mesh with a $2 \mathrm{~mm}$ grid size was etched onto the specimens. The strains were then evaluated optically by an AutoGrid 4.1 Strain Analysis System, which used information from four cameras, each of which recorded 30 images per second during 


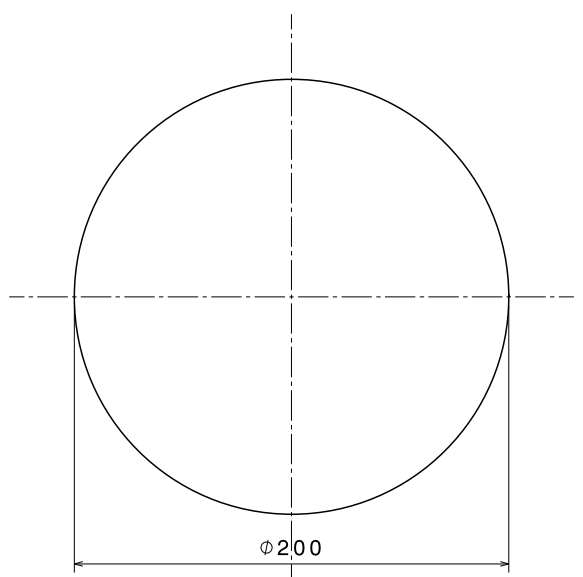

(a)

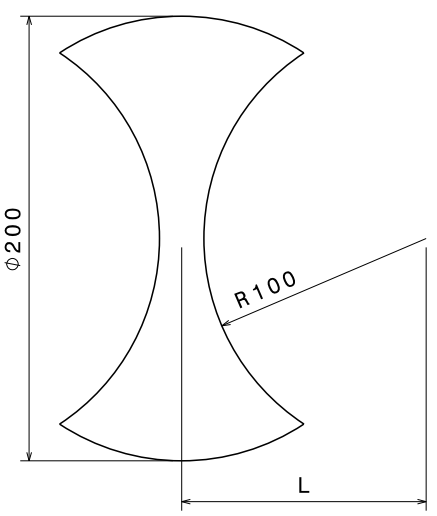

(b)

Figure 25: Nakajima specimen geometry: (a) circular (b) with different waists $(L=130,140,150,160,165$ and $170 \mathrm{~mm})$. Dimensions in $\mathrm{mm}$.

the test. The image just before the fracture was used to evaluate the limit strains, and consequently, the strains may be well past the limit of localised necking. A method similar to the one described by Bragard et al. (1972) was used to evaluate the limit strains at the onset of localised necking. This method is straightforward and the major and minor strain distributions on a few lines across the instability are considered. Afterwards the strains inside the localised region were excluded and a polynomial fit was adapted to the remaining strains. The maximum strain from this polynomial was chosen as the major strain limit, see Figure 26. For the minor strain, a linear fit was performed at the location of the maximum strain.

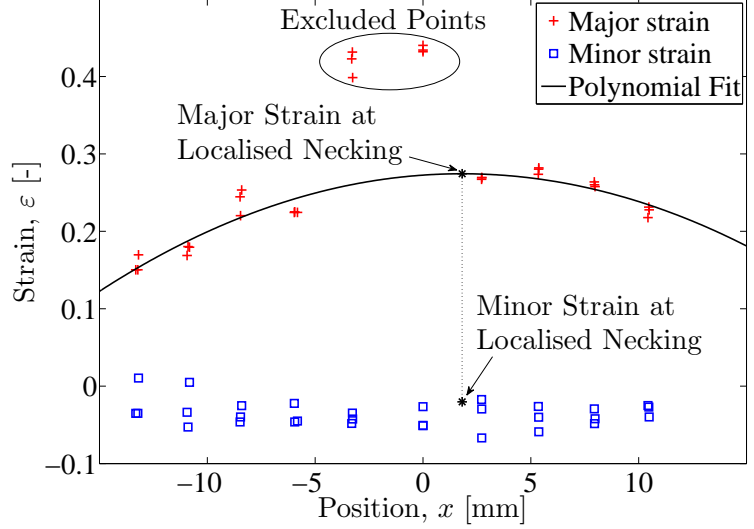

(a)

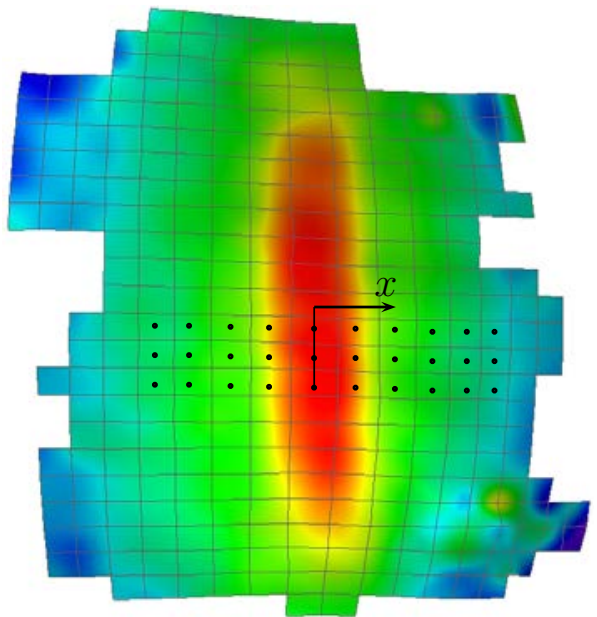

(b)

Figure 26: Illustration of the Bragard et al. (1972) method; (a) polynomial fit to strains and (b) lines of elements across the localisation zone used to evaluate the strain limit. 


\subsection{Exhaust bracket test}

A validation test of fracture prediction during a complex loading situation is described in Paper VI. The test is a two-step forming operation of a sheet metal exhaust bracket, which is subsequently subjected to stretch loading until fracture. Views of the exhaust bracket geometries during the process steps, from blank to fracture, are shown in Figure 27. The dimension of the blank was $40 \mathrm{~mm} \times 218.6$ $\mathrm{mm}$, with its long side parallel to the sheet rolling direction.

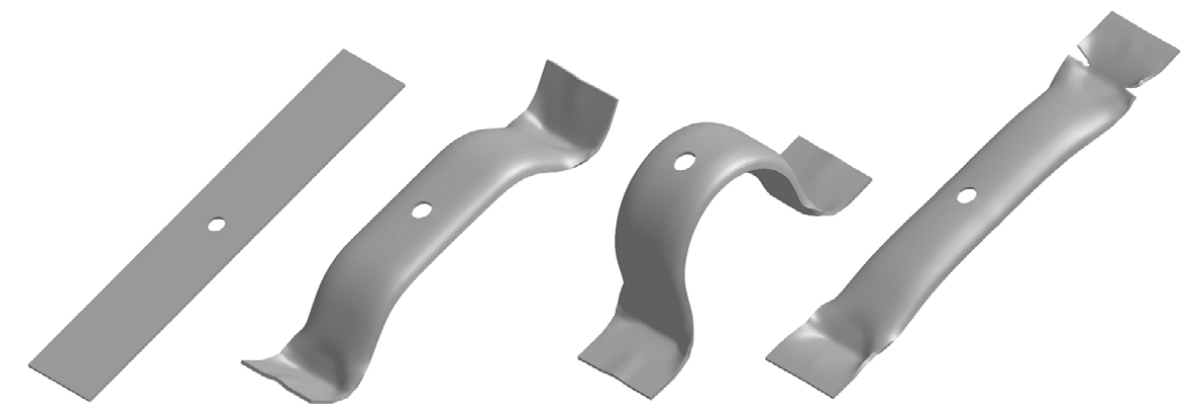

Figure 27: Views of the exhaust bracket geometry during the process steps. From left to right: blank, after forming step 1, after forming step 2, and after fracture in the final stretch test.

The forming tools were mounted in a hydraulic single action press with a punch speed of $60 \mathrm{~mm} / \mathrm{s}$. Lubricant was manually distributed on the blank surface. After each forming step, the geometry was scanned by an ATOS 3D scanner in order to validate the geometries predicted by the $\mathrm{FE}$ simulations.

The subsequent stretching was achieved by subjecting the exhaust bracket to tensile loading until fracture, see Figure 28. During the mounting, the flanges of the exhaust bracket were clamped so that they were aligned parallel to the loading direction. The cross-head velocity was $10 \mathrm{~mm} / \mathrm{min}$.

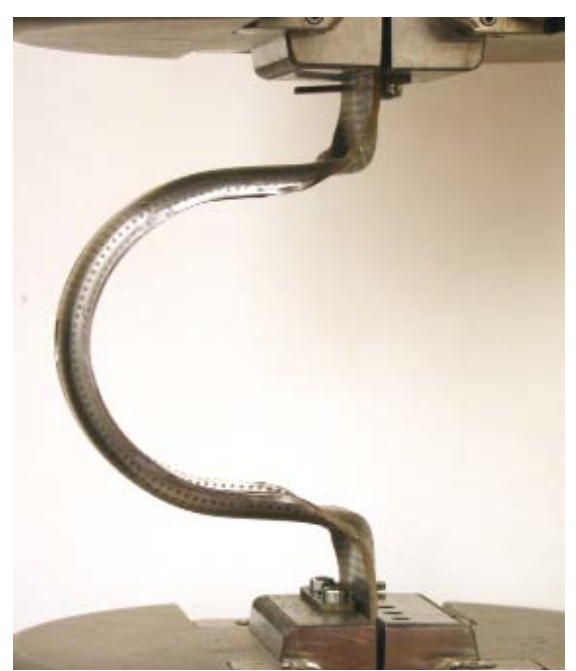

Figure 28: Experimental setup of the exhaust bracket stretch test. 


\section{Review of appended papers}

\section{Paper I}

A study of high strength steels undergoing non-linear strain paths Experiments and modelling

This paper presents an evaluation of the constitutive behaviour, including plastic anisotropy and mixed isotropic-kinematic hardening of two high strength steels, Docol 600DP and Docol 1200M, during strain path changes.

A series of tensile and shear tests was performed on both virgin and pre-strained materials. The initial anisotropy and work hardening parameters were obtained from tensile tests, shear tests and a bulge test of the virgin material, whereas the kinematic hardening parameters were identified by comparing numerical predictions to experimental results related to the pre-strained materials. Numerical predictions using the obtained parameters agree well with the experimental results, both in the case of proportional, and under non-proportional strain paths.

\section{Paper II}

Failure of high strength steel sheet - Experiments and modelling

In this paper the failure of the high strength steel Docol 600DP and the ultra high strength steel Docol 1200M is explored. The constitutive model used in this study includes plastic anisotropy and mixed isotropic-kinematic hardening. For modelling of the ductile and shear fracture the models presented by Cockroft-Latham and Bressan-Williams have been used. The instability phenomenon is described by the constitutive law and the FE models. For calibration of the failure models and validation of the results, an extensive experimental series has been conducted including shear tests, plane strain tests and Nakajima tests. The geometries of the Nakajima tests have been chosen so that the first quadrant of the FLD were covered. The results are presented both in an FLD and using prediction of forcedisplacement response of the Nakajima test employing element erosion during the 
FE simulations. The classical approach for failure prediction is to compare the principal plastic strains obtained from FE simulations with experimental determined FLC. It is well known that the experimental FLC requires proportional strains to be useful. In this work failure criteria, both of the instability and fracture, are proposed which can be used also for non-proportional strain paths.

\title{
Paper III
}

Failure characteristics of a dual-phase steel sheet

In this paper the failure characteristics of the high strength steel Docol 600DP are explored. The study includes both experimental and numerical sections. In the experimental sections, the fracture surface of the sheet subjected to Nakajima tests is studied under the microscope with the aim of finding which failure mechanism causes the fracture. In the numerical sections, FE simulations have been conducted using solid elements. From these simulations, local stresses and strains have been extracted and analysed with the aim of identifying the fracture dependency of the stress triaxiality and Lode parameter.

\section{Paper IV}

\author{
Prediction of fracture in a dual-phase steel subjected to non-linear \\ straining
}

In this paper, selected fracture criteria are applied to predict the fracture of dualphase steel subjected to non-linear strain paths. Furthermore, the effects of manufacturing history are studied. Four fracture criteria were calibrated in three tests using standard specimens. The fracture criteria were first validated in the circular Nakajima test. A second validation test case was included in order to validate fracture prediction for non-linear strain paths. In this test a sheet metal component was manufactured and subsequently stretched until it fractured. All fracture criteria included in this study predict fracture during the Nakajima test with reasonable accuracy. In the second validation test however, the different fracture criteria show considerable diversity in accumulated damage during manufacturing which caused substantial scatter of the fracture prediction in the subsequent stretching. This shows that manufacturing history influences the prediction of fracture. 


\section{Paper V}

\section{Anisotropic fracture criteria for a dual-phase steel}

The main objective of this paper is to examine the use of anisotropic fracture criteria in order to predict fracture in dual-phase steel. The introduction of a material directional function into the fracture criterion was used in order to account for anisotropy observed in experiments. Selected fracture criteria were fist calibrated by ordinary tensile and in-plane shear tests using specimens cut in three material directions. In order to validate the performance, two types of validation tests were conducted. First, plane strain (notched tensile) tests were carried out in three material directions. Second, Nakajima tests with a waist of $130 \mathrm{~mm}$ were conducted, also in three material directions. The fit to the calibration tests was improved with all material directional functions compared to the isotropic criterion. Overall best performance was achieved when a material direction function based on the structural tensors was introduced. 



\section{Conclusions and discussion}

Increased demands for improved weight-to-performance ratios in order to reduce emission from vehicles have favoured the use of high-strength steels in the automotive industry. These structures are mainly subjected to plane stress, or close to plane stress, states. As a consequence, but also due to their computational efficiency, shell elements are used in the FE modelling of these structures. The shell elements place a constraint on the choice of constitutive modelling with industrial applicability in mind. The focus of this work has been to understand and predict ductile fracture in high-strength steel sheets. In order to ensure industrial applicability, this study has been limited to un-coupled fracture criteria since they have few material parameters and are relatively easy to calibrate.

The constitutive model is of significant importance in order to obtain trustworthy results both as concerns the mechanical response and the subsequent fracture prediction. Anisotropic behaviour is often noticed in high-strength steel sheets due to the rolling process used during their manufacturing. Furthermore, a more complex hardening compared to mild steel is often noticed. Hence, during the main part of this work, a constitutive model including plastic anisotropy and mixed isotropic-kinematic hardening has been used.

In Paper I the anisotropy in both yield stresses and plastic flow was accurately captured with the used of the high exponent anisotropic yield function Yld2003. Furthermore, it was concluded that neither isotropic nor kinematic hardening was sufficient to describe plastic hardening during non-linear strain paths. Thus, mixed isotropic and kinematic hardening is required.

Three failure mechanisms have been identified from experimental observation in the use of microscopic studies in Paper III. The failure has been defined as ductile tensile fracture, ductile shear fracture or material instability with localisation. The instabilities have been predicted with good levels of accuracy by the constitutive law and the FE models, both when shell and solid element formulations were used. However, good results require a dense mesh discretisation since the size of the thickness instability is of the same magnitude as the sheet thickness. Concerning the ductile tensile and shear fractures, a variety of models have been examined. In Paper II individual models were used in order to predict the different fracture mechanisms. The ductile tensile fracture was there accurately captured by the Cockroft-Latham criterion despite its simple formulation. However, the ductile 
shear fracture was not accurately captured by the Bressan-Williams criterion.

In Paper IV, selected fracture criteria were applied to predict fracture during non-linear strain paths. Furthermore, the effects of their manufacturing history on product functionality were studied. It was concluded that the manufacturing process must be considered to accurately predict the properties of the final product.

Fracture criteria accounting for anisotropy were examined in Paper V. By coupling different material directional functions to a fracture criterion, anisotropy in fracture was accounted for. The extended Cockroft-Latham criterion was used in this study. However, the modelling technique can be used with other fracture criteria and damage models in a simple manner. All studied material directional functions improved the results from the simulations of the calibration test. However, during the validation of the models, some material directional functions showed unsatisfactory results.

Different approaches may be used when calibrating fracture criteria. It could be argued that the consideration of a wide range of loading conditions using different experiments is a good approach. However, in order to achieve this, a wide range of test equipment is necessary. Since a focus of this study is industrial applicability, the fracture criteria have been calibrated in simple standardised experiments. This approached will restrict the loading conditions that can be applied and also impose demands on the formulation of the fracture criterion. The criterion must be able to capture fracture behaviour over a wide range of loading situations. 


\section{Outlook}

During the course of this work several issues concerning failure prediction have been identified for further research, and some of these are discussed below.

One interesting route to investigate the details of damage and fracture evolution would be to use micro-mechanical modelling. The growth of damage in steel by intergranular and transgranular fracture can be studied with the use of a representative volume element model in order to improve the understanding of macroscopic observations. Results from micro-mechanical modelling could be a means of improving the macroscopic constitutive models, including fracture, necessary for the analysis of engineering structures.

The main topic of this thesis has been to predict failure in high-strength steel by the use of macro-mechanical un-coupled damage models calibrated on results from standard tests. An alternative route would be to use coupled damage models, which possibly would improve the accuracy of the prediction of deformation and failure. However, coupled damage models require substantially more material testing and calibration.

In sheet metal applications one of the main causes of failure is thickness instability. At this instability the material is locally subjected to large strains, which need to be resolved in order to predict the final fracture. It would be interesting to study how structural adaptivity and mesh adaptivity can capture these localisations in order to avoid homogeneously dense FE meshes.

Fairly dense FE meshes have been used in this study to capture deformation and failure. Even though today's FE models of automotive structures are densely meshed, the smallest element is still much larger than the size of the elements in this study. It still remains to investigate how the failure models developed in this study can be used in industrial applications. For example, how should the material fracture parameters obtained in this study be scaled to fit larger element sizes and what would be the best methodology to model crack growth and propagation in an FE mesh?

There are variations in all real material properties. The variation of failure may be particularly large due to different material defects. Consequently, research on how to implement stochastic variations into a failure prediction is necessary. 



\section{Bibliography}

Anderson, T. L., 2005. Fracture Mechanics Fundamentals and Applications. Taylor and Francis Group, New York.

Aretz, H., 2004. Numerical restrictions of the modified maximum force criterion for prediction of forming limits in sheet metal forming. Modelling and Simulation in Materials Science and Engineering 12 (4), 677-692.

Aretz, H., 2005. A non-quadratic plane stress yield function for orthotropic sheet metals. Journal of Materials Processing Technology 168 (1), 1-9.

Aretz, H., Hopperstad, O. S., Lademo, O.-G., 2007. Yield function calibration for orthotropic sheet metals based on uniaxial and plane strain tensile tests. Journal of Materials Processing Technology 186, 221-235.

Aretz, H., Keller, S., Vogt, R., Engler, O., 2011. Modelling of ductile failure in aluminium sheet forming simulation. International Journal of Material Forming 4 (2), 163-182.

Aspenberg, D., Larsson, R., Nilsson, L., 2012. An evaluation of the statistics of steel material model parameters. Journal of Materials Processing Technology 212 (6), 1288-1297.

Bai, Y., Wierzbicki, T., 2010. Application of extended Mohr-Coulomb criterion to ductile fracture. International Journal of Fracture 161, 1-20.

Banabic, D., Barlat, F., Cazacu, O., Kuwabara, T., 2010. Advances in anisotropy and formability. International Journal of Material Forming 3, 165-189.

Belytschko, T., Liu, W. K., Moran, B., 2000. Nonlinear Finite Elements for Continua and Structures. Wiley, Chichester.

Bergström, Y., Granbom, Y., Sterkenburg, D., 2010. A dislocation-based theory for the deformation hardening behavior of DP steels: Impact of martensite content and ferrite grain size. Journal of Metallurgy 2010.

Bragard, A., Baret, J.-C., Bonnarnes, H., 1972. A simplified technique to determine the FLD at the onset of necking. Report No. 33, Rapport Centre de Recherche de la Mètallurgie, Liège. 
Bressan, J., Williams, J., 1983. The use of a shear instability criterion to predict local necking in sheet metal deformation. International Journal of Mechanical Sciences 25 (3), 155-168.

Chaboche, J., 2008. A review of some plasticity and viscoplasticity constitutive theories. International Journal of Plasticity 24 (10), 1642-1693.

Cockroft, M. G., Latham, D. J., 1968. Ductility and the workability of metals. Journal of the Institute of Metals 96, 33-39.

Cowper, G. R., Symonds, P. S., 1957. Strain-hardening and strain-rate effects in the impact loading of cantilever beams. Tech. rep., Division of Applied Mathematics, Brown University.

da Rocha, A. B., Barlat, F., Jalinier, J., 1985. Prediction of the forming limit diagrams of anisotropic sheets in linear and non-linear loading. Materials Science and Engineering 68 (2), 151-164.

Dieter, G. E., 1986. Mechanical Metallurgy. McGraw-Hill, New York.

Eggertsen, P.-A., Mattiasson, K., 2009. On the modelling of the bending-unbending behaviour for accurate springback predictions. International Journal of Mechanical Sciences 51, 547-563.

Frederick, C., Armstrong, P., 2007. A mathematical representation of the multiaxial Bauschinger effect. Materials at High Temperatures 24 (1), 1-26.

Fyllingen, O., Hopperstad, O., Lademo, O.-G., Langseth, M., 2009. Estimation of forming limit diagrams by the use of the finite element method and Monte Carlo simulation. Computers and Structures 87 (1-2), 128-139.

Garrison Jr, W., Moody, N., 1987. Ductile fracture. Journal of Physics and Chemistry of Solids 48 (11), 1035-1074.

Geng, L., Wagoner, R. H., 2002. Role of plastic anisotropy and its evolution on springback. International Journal of Mechanical Sciences 44 (1), 123-148.

Ghosh, A. K., Backofen, W. A., 1973. Strain hardening and instability in biaxially sterched sheets. Metallurgical Transactions 4, 1113-1122.

Goodwin, G. M., 1968. Application of strain analysis to sheet metal forming problems in the press shop. SAE Automotive Engineering Congress.

Gruben, G., Hopperstad, O., Børvik, T., 2012. Evaluation of uncoupled ductile fracture criteria for the dual-phase steel Docol 600DL. International Journal of Mechanical Sciences 62 (1), 133-146.

Gruben, G., Hopperstad, O., Børvik, T., 2013. Simulation of ductile crack propagation in dual-phase steel. International Journal of Fracture 180 (1), 1-22. 
Gurson, A., 1977. Continuum theory of ductile rupture by void nucleation and growth: Part I - Yield criteria and flow rules for porous ductile media. Journal of Engineering Materials and Technology 99 (1), 2-15.

Han, H. N., Kim, K.-H., 2003. A ductile fracture criterion in sheet metal forming process. Journal of Materials Processing Technology 142 (1), 231-238.

Hershey, A. V., 1954. The plasticity of an isotropic aggregate of anisotropic facecentered cubic crystals. Journal of Applied Mechanics 21, 241-249.

Hertzberg, R. W., 1996. Deformation and Fracture Mechanics of Engineering Materials. John Wiley, New York.

Hill, R., 1948. A theory of the yielding and plastic flow of anisotropic metals. Proceedings of the Royal Society of London. Series A, Mathematical and Physical Sciences 193 (1033), 281-297.

Hill, R., 1952. On discontinuous plastic states, with special reference to localized necking in thin sheets. Journal of the Mechanics and Physics of Solids 1 (1), $19-30$.

Hockett, J. E., Sherby, O. D., 1975. Large strain deformation of polycrystalline metals at low homologous temperatures. Journal of the Mechanics and Physics of Solids 23, 87-98.

Hollomon, J. H., 1945. Tensile deformation. Transaction of the American Institute of Mining, Metallurgical and Petroleum Engineers 162, 268-290.

Hooputra, H., Gese, H., Dell, H., Werner, H., 2004. A comprehensive failure model for crashworthiness simulation of aluminium extrusions. International Journal of Crashworthiness 9 (5), 449-63.

Hora, P., Tong, L., Reissner, J., 1996. A prediction method for ductile sheet metal failure in FE-simulation. Proceedings of the 3rd International Conference Numisheet'96, Dearborn, Michigan, 252-256.

Hosford, W., 1993. The Mechanics of Crystals and Textured Polycrystals. Oxford Science Publications, New York.

Hosford, W., Cadell, R., 1993. Metal Forming Mechanics and Metallurgy. PrentisHall, New York.

Hosford, W. F., 2005. Mechanical Behavior of Materials. Cambridge University Press, New York.

ISO, 2008. Metallic materials - sheet and strip - determination of Forming Limit Curves - Part 2: Determination of Forming Limit Curves in the Laboratory. Austrian Standards Institute, Wien, 12004-2:2008.

Johnson, G. R., Cook, W. H., 1983. A constitutive model and data for metals subjected to large strains high strain rates and high temperatures. Seventh International Symposium on Ballistics, Hague, 1-7. 
Johnson, G. R., Cook, W. H., 1985. Fracture characteristics of three metals subjected to various strains, strain rates, temperatures and pressures. Engineering Fracture Mechanics 21 (1), 31-48.

Keeler, S. P., Backofen, W. A., 1963. Plastic instability and fracture in sheets stretched over rigid punches. Transactions of the ASM 56, 25-48.

Lademo, O.-G., Berstad, T., Hopperstad, O. S., Pedersen, K. O., 2004a. A numerical tool for formability analysis of aluminium alloys. Part I: Theory. Steel Grips 2, 427-432.

Lademo, O.-G., Engler, O., Keller, S., Berstad, T., Pedersen, K., Hopperstad, O., 2009. Identification and validation of constitutive model and fracture criterion for AlMgSi alloy with application to sheet forming. Materials and Design 30 (8), 3005-3019.

Lademo, O.-G., Pedersen, K., Berstad, T., Furu, T., Hopperstad, O., 2008. An experimental and numerical study on the formability of textured AlZnMg alloys. European Journal of Mechanics - A/Solids 27 (2), 116-140.

Lademo, O.-G., Pedersen, K. O., Berstad, T., Hopperstad, O. S., 2004b. A numerical tool for formability analysis of aluminium alloys. Part II: Experimental validation. Steel Grips 2, 433-437.

Larsson, R., 2012. On material modelling of high strength steel sheets. Ph.D. Thesis, Linköpings Univeristy, Linköping.

Lemaitre, J., 1985. A continuous damage mechanics model for ductile fracture. Journal of Engineering Materials and Technology 107, 83-89.

Lemaitre, J., Chaboche, J.-L., 1990. Mechanics of Solid Materials. Cambridge University Press, Cambridge.

Li, H., Fu, M., Lu, J., Yang, H., 2011. Ductile fracture: Experiments and computations. International Journal of Plasticity 27 (2), 147-180.

Lode, W., 1926. Versuche über den einfluß der mittleren hauptspannung auf das fließen der metalle eisen, kupfer und nickel. Zeitschrift für Physik 36, 913-939.

Luo, M., Dunand, M., Mohr, D., 2012. Experiments and modeling of anisotropic aluminum extrusions under multi-axial loading - Part II: Ductile fracture. International Journal of Plasticity 32-33 (0), 36-58.

Marciniak, Z., Kuczyński, K., 1967. Limit strains in the processes of stretchforming sheet metal. International Journal of Mechanical Sciences 9 (9), 609-620.

Marciniak, Z., Duncan, J., Hu, S., 2002. Mechanics of sheet metal forming. Butterworth-Heinemann, Oxford. 
Metals Handbook, 1974. Interpretation of Transmission-Electron-Microscope Fractographs, in Metals Handbook, 8th Ed., Vol. 9. American Society for Metals, Metals Park.

Needleman, A., 1985. On finite element formulations for large elastic-plastic deformations. Computers and Structures 20, 247-257.

Olsson, K., Gladh, M., Hedin, J.-E., Larsson, J., 2006. Microalloyed high-strength steels. Advanced Materials and Processes 164 (8), 44-46.

Opbroek, E. G., 2009. Advanced high strength steel application guidelines. Tech. Rep. WorldAutoSteel.

Pietruszczak, S., Mroz, Z., 2000. Formulation of anisotropic failure criteria incorporating a microstructure tensor. Computers and Geotechnics 26 (2), $105-112$.

Shinozuka, M., Deodatis, G., 1996. Simulation of multi-dimensional Gaussian stochastic fields by spectral representation. Applied Mechanics Reviews 49, $29-53$.

Sigvant, M., Mattiasson, K., Vegter, H., Thilderkvist, P., 2009. A viscous pressure bulge test for the determination of a plastic hardening curve and equibiaxial material data. International Journal of Material Forming 2 (4), 235-242.

Stoughton, T. B., 2000. A general forming limit criterion for sheet metal forming. International Journal of Mechanical Sciences 42 (1), 1-27.

Stören, S., Rice, J., 1975. Localized necking in thin sheets. Journal of the Mechanics and Physics of Solids 23 (6), 421-441.

Swift, H. W., 1952. Plastic instability under plane strain. Journal of the Mechanics and Physics of Solids, 1, 1-18.

Tarigopula, V., Hopperstad, O., Langseth, M., Clausen, A., Hild, F., 2008. A study of localisation in dual-phase high-strength steels under dynamic loading using digital image correlation and FE analysis. International Journal of Solids and Structures 45 (2), 601-619.

Tarigopula, V., Langseth, M., Hopperstad, O., Clausen, A., 2006. Axial crushing of thin-walled high-strength steel sections. International Journal of Impact Engineering 32 (5), 847-882.

Teirlinck, D., Zok, F., Embury, J., Ashby, M., 1988. Fracture mechanism maps in stress space. Acta Metallurgica 36 (5), 1213-1228.

Voce, E., 1948. The relationship between stress and strain for homogenus deformation. Journal of the Institute of Metals 74, 537-562.

Wierzbicki, T., Bao, Y., Lee, Y.-W., Bai, Y., 2005. Calibration and evaluation of seven fracture models. International Journal of Mechanical Sciences 47 (4-5), 719-743. 
Yamaguchi, K., Adachi, H., Takakura, N., 1998. Effects of plastic strain path on Young's modulus of sheet metals. Metals and Materials 4, 420-425.

Yoshida, F., Uemori, T., 2002. A model of large-strain cyclic plasticity describing the Bauschinger effect and workhardening stagnation. International Journal of Plasticity 18, 661-686.

Yoshida, F., Uemori, T., 2003. A model of large-strain cyclic plasticity and its application to springback simulation. International Journal of Mechanical Sciences 45 (10), 1687-1702.

Yoshida, F., Uemori, T., Fujiwara, K., 2002. Elastic-plastic behavior of steel sheets under in-plane cyclic tension-compression at large strain. International Journal of Plasticity 18 (5-6), 633-659.

Yoshida, K., Kuwabara, T., Kuroda, M., 2007. Path-dependence of the forming limit stresses in a sheet metal. International Journal of Plasticity 23 (3), $361-384$. 
Part II

Appended papers 



\section{Papers}

The articles associated with this thesis have been removed for copyright reasons. For more details about these see:

http://urn.kb.se/resolve?urn=urn:nbn:se:liu:diva-105213 